\title{
Measuring temperature-related mortality using endogenously determined thresholds
}

\author{
Thomas Longden \\ Centre for Health Economics Research and Evaluation - University of Technology Sydney
}

July 2018

\begin{abstract}
$\underline{\text { Abstract }}$
Heat-related mortality tends to be associated with heatwaves that do not allow for sufficient acclimatisation to hot weather. In contrast, damage functions and most heatwave emergency response plans do not account for acclimatisation. Using an excess heat measure that accounts for acclimatisation, this paper produces estimates of temperature-related mortality for the five largest Australian capital cities. Fixed effects panel threshold regressions are applied to establish the thresholds that coincide with heightened mortality during extreme temperature events. The estimated parameters associated with these thresholds are then used to develop hindcast estimates for cold temperatures, moderate temperatures, hot temperatures and extreme heat. The estimated thresholds coincide with a notable impact of hot weather on mortality, but a limited cold weather impact. This shows that the burden of risk associated with mortality related to future temperatures and climate change within Australia coincides with heatwaves rather than coldwaves. This is in contrast to recent studies that found that cold weather-related mortality within Australian capital cities has and will continue to be notable. These studies also found a net benefit from climate change in Australia due to reduced cold weather deaths.
\end{abstract}

Keywords: heatwave; mortality; threshold regression

JEL Classification: I10; Q54; C24; C5

Correspondence: thomas.longden@chere.uts.edu.au

Word Count: 5,143 (main text only)

No. of Figures: 2; No. of Tables: 2.

The author thanks the Australian Bureau of Statistics for daily all-cause mortality data and two anonymous reviewers for useful feedback and comments. The usual disclaimers apply. 


\section{INTRODUCTION}

Temperature-related mortality has been identified as a key detrimental impact of rising temperatures related to climate change (Smith et al. 2014). This is reflected in the inclusion of a temperature-mortality relationship in a widely used damage function (Tol 2002a) that has been integrated into the FUND (Tol 2002b; Tol 2013), ENVISAGE (Roson and Van der Mensbrugghe 2012) and GTAP-E (Bosello et al. 2006) integrated assessment models (IAMs). Amongst the criticisms of this damage function, which was built using a meta-analysis conducted by Martens (1998), is the lack of accounting for the impact of acclimatisation on the temperature-mortality relationship and the invalidity of applying a uniform $\mathrm{V}$-shaped temperature-mortality relationship across a range of regions (Ackerman and Stanton 2008; Huber et al. 2017). A major issue with the V-shaped relationship developed in Martens (1998) and utilised in Tol (2002a) is that it has been found to be biased towards cold-related mortality and that this is likely to have led to bias towards finding a net reduction in mortality associated with climate change (Huber et al. 2017). As previous studies have found different shapes for the temperature-mortality relationship depending upon the city/climate focused upon (Analitis et al. 2008; Gasparrini et al. 2015; Gasparrini et al. 2017; Gosling et al. 2009; Gronlund et al. 2016; Guo et al. 2014); it is likely that the application of a coldbiased temperature-mortality relationship to tropic, sub-tropic and temperate regions with warm summers will be problematic. The importance of assessing the nature of the temperature-mortality relationship using different techniques and data from a range of climatic regions is important as previous studies, which includes Guo et al. (2016) and Gasparrini et al. (2017), have found net benefits of climate change that are associated with decreased cold-related deaths in regions that are subject to extremely warm temperatures.

In light of this, this paper estimates temperature-related mortality thresholds that account for a lack of acclimatisation to extreme weather while also making an adjustment for short-term mortality displacement. These thresholds capture levels of temperature where the temperature-related mortality relationship differs. Fixed effects panel threshold regressions are used to endogenously determine the thresholds that coincide with heightened mortality during and after heatwave and coldwave events. The analysis utilises daily temperature and mortality data from the five largest Australian capital cities for the period between 2001 and 2015. These five capital cities are the focus of this paper as they encompass climates that are sub-tropical or temperate with warm summers. Once differences across regions, seasons and climate variability are accounted for, these regions are found to coincide with a temperature-mortality relationship that has a minor or negative coldwave element and a notable 
heatwave element. Some of the reasons that this temperature-mortality relationship is different to that found in previous studies, such as Gasparrini et al. (2015), Guo et al. (2016) and Gasparrini et al. (2017), are how seasonality is accounted for, the use of a temperature measure that accounts for prevailing temperatures in that region, and the use of a fixed effects model to allow for the number of deaths that occur on any given day.

One of the aims of this research is to show that it is possible to use endogenously determined thresholds and the associated model estimates to develop damage functions or forecasts of temperature-related mortality in Australia and analogue regions. This approach is important as there is no need for assumptions about the shape of the temperature-mortality relationship or exogenous threshold temperatures. However, rather than assessing the impact of these estimates within a damage function or applying these estimates to different analogue regions; in this paper, these estimates are used to produce hindcasts that assess whether the risk of mortality for these five cities coincides with cold weather and/or hot weather. This will be assessed by separating the hindcasts produced into the mortality associated with low, moderate, high and extremely high temperatures. Note that these four groups are those captured by the endogenously determined thresholds and were not predetermined.

Kinney et al. (2008) identified a set of challenges for forecasting the future health consequences of higher temperatures. These challenges were to utilise a historical exposure function that is built for a specific city/region or an analogue climate; to utilise an appropriate minimum mortality threshold that allows for differences in acclimatisation/adaptation; and the allowance for moderators (such as access to air conditioning). In addition to being important for long term assessments of climate change damages and forecasting; these issues are also relevant to the present day as existing heatwave response plans rarely account for region specific thresholds and acclimatisation (Yardley et al. 2011). Note that recent research has found that the impact of heatwaves and coldwaves on health service utilisation differs between urban and rural areas (Jegasothy et al. 2017). 


\section{METHODOLOGY AND DATA}

\subsection{Methodology}

\subsubsection{Specification of extreme heat and extreme cold events}

The temperature measure used in this study is an Excess Heat Index that accounts for acclimatisation and is part of the Excess Heat Factor (EHF) produced by the Australian Bureau of Meteorology (BOM) (Nairn and Fawcett 2015; Nairn et al. 2013). The EHF measure uses the conditional multiplication of two indices that account for the significance of the event (EHI_S) and the level of acclimatisation to warmer temperatures (EHI_A). The focus on the EHI_A measure is based on previous research, including Langlois et al. (2013), Scalley et al. (2015), HatvaniKovacs et al. (2016), Loridan et al. (2016) and Jegasothy et al. (2017), that found that the EHF is a superior measure of the impact of heat on mortality and health service utilisation. Note that only the EHI_A part of the EHF measure is used in this paper as it can be readily applied within fixed effects panel threshold regressions. As there is no need for an exogenous threshold (as would be the case for the EHI_S component of the EHF measure), the interpretation of the endogenously determined threshold is straightforward and is in units of degrees Celsius. The specification of the EHI_A measure is presented in equation one, with DAT denoting the daily average temperature (calculated using the maximum temperature and minimum temperature) and ThrDAT the three-daily average temperature. The subscript $t$ denotes each day during this period for each geographic area, $i$. The EHI_A measure captures the impact of prolonged periods of heat and cold. This is reflected in the use of a two indices measure for both heatwaves (i.e. the EHF) and coldwaves (i.e. the Excess Cold Factor (ECF) has an excess cold index that is computed in the same way as the EHI_A) (Nairn et al. 2013). The ECF has been used in a range of recent papers and these include Wang et al. (2016), Jegasothy et al. (2017) and Piticar et al. (2018).

$E H I \_A_{i t}=T h r D A T_{i t}-\left(D A T_{i t-1}+\cdots+D A T_{i t-30}\right) / 30$

As the EHI_A is a measure that captures whether three daily average temperatures are notably different to the thirty-day average it accounts for the level of acclimatisation to warmer temperatures using historical data specific to that region. A lack of acclimatisation is an issue due to the physiological impact on thermoregulation, as well as, the likelihood that people are prepared for and adapt to extreme heat events. Note that it will be important to distinguish between physiological acclimatisation, behavioural adaptation, and planned adaptation, such as subsidies of air conditioning installations and heat health warning systems (Gosling et al. 2016). This paper does not make this distinction and solely accounts for acclimatisation by estimating the impact of heat using the EHI_A measure. 


\subsubsection{Specification of the threshold model}

To determine the temperature thresholds that coincide with temperature-related mortality, this paper utilises fixed effects panel threshold regressions to identify the range of temperatures that have a notable impact on mortality. This estimation procedure was initially proposed in Hansen (1999) and has been implemented in Stata as the 'xthreg' command (refer to Wang (2015) for further details of this approach and its implementation in Stata). A simple description of the approach is that threshold regressions are used to separate the observations of a variable into classes (or regimes) that are distinguished from each other by different coefficient estimates of a given dependent variable. In this case, the dependent variable is the EHI_A measure.

This study utilises a three threshold model due to the expectation that the relationship between temperature and mortality will be different at low, moderate, high and extremely high temperatures. Using a three threshold model produces a temperature-related mortality curve that has different slopes for four distinct ranges of temperatures. This formulation is flexible and can capture the U- shaped, V-shaped or J-shaped temperature-mortality response that have been found (or discussed) in a range of studies. These studies include Martens (1998), Davis et al. (2003), Baccini et al. (2008), Anderson and Bell (2009), Gasparrini et al. (2015) Dang et al. (2016) and Gasparrini et al. (2017). Confirmation of the number of thresholds to use in the models has also been assessed using a threshold effect F-test produced by the 'xthreg' command, as well as, the overall model fit via the Akaike information criterion (AIC). While a four threshold model is possible, I have not assessed it as this command is limited to three thresholds. The model for three thresholds is specified as:

$M_{i t}=\left\{\begin{array}{c}\left(\boldsymbol{E H I} \boldsymbol{A}_{i t}\right)\left(\boldsymbol{\beta}_{1}\right)+\boldsymbol{Z}_{i t} \boldsymbol{\alpha}+u_{i}+e_{i t}, \boldsymbol{E H I} \boldsymbol{A}_{i t}<\gamma_{1} \\ \left(\boldsymbol{E} \boldsymbol{H} \boldsymbol{I}_{-} \boldsymbol{A}_{i t}\right)\left(\boldsymbol{\beta}_{2}\right)+\boldsymbol{Z}_{i t} \boldsymbol{\alpha}+u_{i}+e_{i t}, \gamma_{1} \leq \boldsymbol{E} \boldsymbol{H} I_{-} \boldsymbol{A}_{i t}<\gamma_{2} \\ \left(\boldsymbol{E} \boldsymbol{H} \boldsymbol{A}_{i t}\right)\left(\boldsymbol{\beta}_{3}\right)+\boldsymbol{Z}_{i t} \boldsymbol{\alpha}+u_{i}+e_{i t}, \gamma_{2} \leq \boldsymbol{E H} \boldsymbol{H}_{-} \boldsymbol{A}_{i t}<\gamma_{3} \\ \left(\boldsymbol{E} \boldsymbol{H} \boldsymbol{I}_{-} \boldsymbol{A}_{i t}\right)\left(\boldsymbol{\beta}_{4}\right)+\boldsymbol{Z}_{i t} \boldsymbol{\alpha}+u_{i}+e_{i t}, \boldsymbol{E} \boldsymbol{H} \boldsymbol{I}_{-} \boldsymbol{A}_{i t} \geq \gamma_{3}\end{array}\right.$

where $M_{i t}$ is the level of mortality on that day, $E H I_{-} A_{i t}$ is a column vector of order sixteen and captures the heat measure used in the model (including a contemporaneous and 15 lagged variables) and $Z_{i t}$ is a column vector of explanatory variables. Mortality will be specified as the number of deaths per region and the number of deaths per 100,000 people. The daily data used to estimate the threshold models encompasses the period between February 2001 and December 2015. Estimating the threshold model produces estimates for $\beta_{1,2,3,4}$, which are row vector of coefficients for the temperature measure, and $\alpha$, a row vector of coefficients for the other explanatory variables. $\gamma_{1,2,3}$ are the estimated thresholds and the error terms are $u$ and $e$. It is important to note that the $\gamma$ 
estimates are endogenously determined as they are the values that minimise the residual sum of squares (RSS) using a sequential estimation procedure. The use of fixed effects captures unobserved differences in mortality across regions that are correlated with the explanatory variables in the model.

The explanatory variables are grouped into six types of variables and these include dummy variables for the days of the week, months of the year, the calendar year and days with low mortality. Table 1A in the appendix lists the explanatory variables included in the threshold model estimation and provides summary statistics for these variables for the whole sample (using the capital city geography). The low and very low mortality dummy variables capture outlier days that have a number of deaths lower than $25 \%$ and between $25 \%$ and $50 \%$ of the monthly average. Seasonality is accounted for using the months of the year as it is important to capture differences in the level of mortality during winter and summer. It is expected that increases in deaths during winter months are associated with the influenza season and related pneumonia deaths. Note that previous research on coldwaves controlled for influenza as a separate cause of death (Díaz et al. 2015; Montero et al. 2010). The proportion of elderly people (i.e. over 75 years old) within the population is an important variable capturing the risk-exposure to temperature-related mortality that differs across the regions and is correlated with the fixed effect component of the model.

\subsubsection{Accounting for mortality displacement}

To account for mortality displacement fifteen lags of the EHI_A extreme heat measure are included in the model. The aggregated estimates from all sixteen coefficients will be referred to as short-term mortality displacement. For further background on short-term mortality displacement refer to Box 1A in the appendix. Accordingly, displacement is limited to a maximum of 15 days after the extreme heat event. Otherwise, the usual level of morbidity is captured in the daily and seasonal variables, as well as the fixed effect term for each capital city. As the $E H I_{-} A_{i t}$ measure is included with numerous lags, the model is specified as a finite distributed lag model with one contemporaneous and fifteen lags of the EHI_A measure. These lags are included as regime-dependent variables in the threshold model and are accounted for in the determination of $\gamma_{1,2,3}$. Similar distributed lag models have been used to account for mortality displacement in numerous studies (Allen and Sheridan 2018; Armstrong et al. 2017; Qiao et al. 2015). In accordance with this approach, the estimates associated with EHI_A should be 
interpreted as temperature-related mortality that is adjusted for a short-term displacement period of 16 days. It is expected that the lag variables will capture displacement via negative parameter estimates associated with the EHI_A measure. These estimates and forecasts are the temperature-related deaths that would not otherwise have happened for another reason during the day of and fifteen days after the extreme heat event. At times, the sum of the estimates associated with the contemporaneous and lagged EHI_A variables will be referred to as short-term displacement adjusted temperature-related mortality. Note that the use of lags is also important due to research that found that high temperature-related mortality tends to occur no more than three days after the extreme heat event (Gosling et al. 2009; Guo et al. 2014; Langlois et al. 2013).

\subsubsection{Calculating hindcast estimates of temperature-related mortality}

Equation three specifies how the temperature-related mortality hindcasts (shown as a column vector, $H M$ ) are derived using the EHI_A measure. Equation three combines the mortality estimates per 100,000 people with data on the population (Pop) of these capital cities between 2001 and 2015. Note that Pop is specified as the population of these cities in hundreds of thousands to match the mortality estimates.

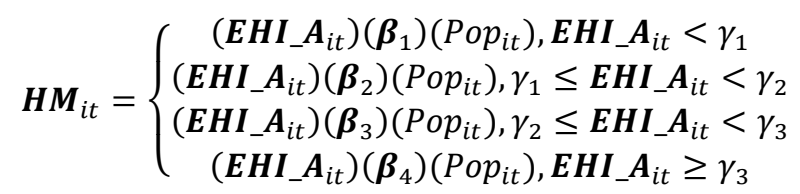

\subsection{Data}

Daily temperature data has been accessed from the BOM website for 21 different weather stations. These weather stations and how they map to the capital city regions is shown in Table $2 \mathrm{~A}$ within the appendix. The data sourced from the $\mathrm{BOM}$ website are the daily maximum temperature and the daily minimum temperature for the 24 hour period leading up to $9 \mathrm{am}$. As the BOM temperature data corresponds to the 24 hours leading up to 9am, the daily maximum temperature data has been adjusted so that it is associated with the day that the mortality occurred. A contemporaneous match between the daily maximum temperature and the mortality variables occurs with this adjustment as the observations of the daily maximum temperature have been moved backwards by one day ${ }^{1}$. This

\footnotetext{
${ }^{1}$ This means that the daily maximum temperature data reported by the BOM for January 1 becomes the observation for December 31 .
} 
adjustment has not been made for the daily minimum temperature data as this variable will capture the temperature of the night preceding mortality and is consistent with research that specified a similar variable to capture the impact of a hot night due to a lack of recovery from heat-stress (Bouchama 2004; D'Ippoliti et al. 2010).

The daily all-cause of death mortality data has been provided by the Australian Bureau of Statistics (ABS) as part of a customised data request from their catalogue of death statistics (Cat. No. 3302.0) that are sourced from Registries of Births, Deaths and Marriages in the relevant regions (ABS 2016). This data has been provided for each major Australian capital city (i.e. Sydney, Melbourne, Brisbane, Adelaide and Perth) and 15 sub-city areas within these capital cities. Note that these cities have a large geographic spread and on the same day there can be notable differences in temperatures between coastal and inland areas. The capital city data is provided at the ABS Greater Capital City Statistical Division (GCCSD) level and the sub-city areas are amalgamations of Level 4 ABS Statistical Areas. Further details and maps of these geographic areas can be accessed from ABS (2010). Note that the sub-city regions have tended to be split based on groupings that coincide with eastern/western or coastal/inland regions. Table $2 \mathrm{~A}$ in the appendix contains the matching of the 20 regions to the BOM weather stations used as the source of the temperature data. Population data from the ABS was used to create mortality per 100,000 people variables for both regional aggregations (ABS 2018) and to specify the Pop variable in equation 3.

Table 1 contains summary statistics on mortality (both measures) and the EHI_A measure for each geographic region. Note that a balanced panel has been created by replacing a small number of missing values from individual weather stations with data from another weather station in that capital city (i.e. those matched to the GCCSD areas). Between 2001 and 2015, Melbourne and Adelaide were the cities with the highest EHI_A levels. This corresponds with extreme heatwaves in South East Australia during 2009, 2014 and 2015. 


\section{RESULTS}

The estimation results from the threshold model estimation that uses the All Capital Cities (i.e. ABS GCCSD) and All City Areas (i.e. the amalgamations of ABS Statistical Area) geographic specifications are shown in the appendix. Before focusing on these estimation results, it should be noted that estimations were also conducted using an extreme heat measure that does not account for acclimatisation (i.e. ThrDAT); however, the thresholds associated with this measure did not produce a temperature-related mortality curve with the expected temperaturemortality response that has been found in previous studies. Accordingly, these estimation results are not presented in this paper. The appropriateness of a three threshold model has been confirmed using AIC statistics and the threshold effect F-test produced by the 'xthreg' command. These statistics and an accompanying discussion are provided within the appendix in Table $3 \mathrm{~A}$.

Overall, the estimation results of the four models shown in Tables 4A and 5A are similar. The highest threshold for the All Capital Cities and All City Areas geographic specifications are quite close to each other. The highest EHI_A threshold values are 7.26 and 7.98 for the mortality per region regressions. These values are 7.26 and 6.71 for the mortality per 100,000 people regressions. For the All Capital Cities specification, the largest increase in mortality that is associated with the EHI_A measure occurs on the second day after the extreme heat event. This is consistent with the findings of Langlois et al. (2013) that found that an "elevation in Excess Heat Factor values preceded the increase in heat-related deaths by 2-3 days" (Langlois et al. 2013). The oscillation in negative and positive estimates that are associated with the EHI_A measure for different thresholds and different numbers of lags is evidence that mortality displacement has been occurring. Mortality displacement is particularly evident in the All City Areas mortality per region regression with statistically significant negative coefficients for the highest threshold occurring four, ten and fourteen days after the extreme heat event. Mortality displacement occurs in all regressions as statistical significant negative coefficients tend to coincide with the highest threshold one or two days after a statistically significant positive coefficient occurs.

As part of sensitivity testing of the model, estimations with six lags of the EHI_A measure have been estimated and these results are shown in Tables 6A and 7A. Consistent results are found as the EHI_A threshold values for these reduced models are 7.26, 7.98, 7.26 and 7.98. These values are very close matches to the thresholds presented 
in Tables 4A and 5A. In all cases, the largest increase in mortality occurs on the second day after the extreme heat event, irrespective of whether 15 or 6 lags are used.

To assist with the interpretation of the relationship between the EHI_A measure and mortality, Figure 1 contains the accumulated sixteen day temperature-related mortality that is associated with values of EHI_A between -12 and 12. These accumulated sixteen day estimates incorporate all of the contemporaneous and lagged parameters associated with the EHI_A measure. Across all four model specifications there is a notable impact of extreme heat that coincides with a EHI_A greater than 6.71. In all cases, there is a high impact of extreme heat, a moderate impact of high heat, a low or negative impact of moderate temperatures and a low or negative impact of low/cold temperatures. Note that all of these temperature-mortality functions are dissimilar to those found in Martens (1998), Gasparrini et al. (2015), Guo et al. (2016) and Gasparrini et al. (2017). While Guo et al. (2016) forecasted temperature-related mortality for three Australian capital cities, it should be noted that Adelaide, a city that was harshly impacted by severe heatwaves in 2009, was not included within their analysis. Also, the control of longterm trends and seasonality in Gasparrini et al. (2015), Guo et al. (2016) and Gasparrini et al. (2017) was conducted using a smooth non-linear functional form in a time-series model that is notably different from the approach used in this paper. Martens (1998) imposed a V-shaped relationship rather than endogenously determining the shape of the temperature-mortality relationship as done in this paper.

As there are between 2 to 6 sub-city regions within a capital city, differences in the size of reference region explains why the imputed deaths for the two geographic specifications differ even though the thresholds are so similar. Adjustment for the size of the at-risk population should be made when these estimates are applied to produce hindcasts/forecasts for the city level (as specified in equation 3). This approach should be used when applying these results to other analogue regions.

Another important issue is that three cities have had notably high exposures to heatwave events. Based on the historical statistics of the EHI_A measure from 2001 to 2015, these cities are Melbourne, Adelaide and Perth. This evident in Table 1c as Melbourne, Adelaide and Perth are those cities that had EHI_A values above 9 during the 2001 to 2015 period. This is also evident in Figure 2a, which shows the hindcasts for the All Capital Cities 
model with the dependent variable specified as mortality per 100,000 people. These same three cities have had higher mortality per 100,000 people than the two more northern cities (which are closer to the equator and typically warmer). This reflects the importance of a lack of acclimatisation in the temperature-mortality relationship.

Figure $2 \mathrm{~b}$ contains hindcasts that have been upscaled using the city-level population data from the ABS (as specified in equation 3). These hindcasts have been produced using the relationship in Figure 2a (based on the All Capital Cities estimations in Table 5A) to show the differences in the impact per city based on the size of their atrisk population. In this case, Melbourne stands out as it is a large city that has had a notable number of deaths per 100,000 people. The number of deaths in Sydney is also high and this is due to the size of the at-risk population as Sydney is the most populous city in Australia. Adelaide and Perth have relatively high numbers of deaths with respect to the size of their populations. Brisbane (which is the city closest to the equator and in a region classed as sub-tropical) has had the lower number of temperature-related deaths based on these results, which use the EHI_A measure. Whether this occurs using other measures will be of interest in future research.

The highest number of heat-related deaths coincided with the years 2009, 2011, 2014 and 2015. 2009 is the year of a severe heatwave that impacted South East Australia and occurred in two stages between 27-31 January and 6-8 February. During that period Adelaide had its warmest night on record with a minimum of $33.9^{\circ} \mathrm{C}$ on the morning of January 29 and the city also equalled a 1908 record of six consecutive days with a temperature above $40^{\circ} \mathrm{C}$ (BOM 2009). During the period between the $27^{\text {th }}$ and $30^{\text {th }}$ January, Adelaide had the highest EHI_A values in the dataset with four days of EHI_A values above 10. This included two days with levels of EHI_A above 12.5. For the period between January 27 and February 5, Langlois et al. (2013) identified 58 deaths in Adelaide that were "reported to the Coroner in which exposure to high ambient temperature was regarded to have caused or significantly contributed to the death" (Langlois et al. 2013). In 2014, Melbourne experienced temperatures above $41^{\circ} \mathrm{C}$ on all days between January 14 and 17 . This period was associated with 167 excess deaths in a report by the Victorian Department of Health (Vict. Dept. of Health 2014). The end of 2015 was also an extremely hot period for Adelaide and Melbourne (Australian Associated Press 2015; Wahlquist 2015), which is captured in the hindcasts for 2015 as the EHI_A measure for this period is above 8 for both cities. 


\section{DISCUSSION}

The estimates presented in this paper are the number of deaths related to extreme temperatures that would not have otherwise occurred in the next fifteen days and are not associated with seasonality. Upon interpreting the results of this paper it should be noted that many of these regions implemented heatwave emergency response plans after 2009. While a study has evaluated the effectiveness of a heat warning system in Adelaide (Nitschke et al. 2016), whether these policy interventions have been successful and reduced the rate of heat-related deaths in other Australian capital cities will be the subject of future research. Reviewing the annual dummy variables shows an increase in mortality in later years; however, little can be said about the impact of the heatwave emergency response plans implemented after 2009 as controlling for a range of issues, such as the prevailing weather extremes, would need to occur. The hindcasts in this paper should be treated as the exposure to temperaturerelated mortality based on the relationship and the practices in place in these cities between 2001 and 2015. Changes in adaptation occur and this is a separate issue from acclimatisation that is based on thermoregulatory disfunction and the other drivers of these results.

Five year hindcast estimates for four categories of temperatures are shown in Table 2. Consistent with the thresholds estimated, the large majority of deaths were associated with high and extremely high temperature events. There is a negative impact of extremely low temperatures across all of the cities and this suggests that the burden of risk from future weather events in Australian capital cities will be associated with heat events rather than cold weather events. Brisbane has had less deadly heatwave events in comparison to the other major Australian capital cities and this corresponds with the patterns across cities captured in the 2001-2015 estimates (shown in Figure 2a and Table 1c).

Based on these results, the downward trend in temperature-related mortality found for Melbourne in Guo et al. (2016) for the period between 2000 and 2100 will not be replicated as a historical U- or V-shaped relationship is not found in this study. Guo et al. (2016) also found that climate change will decrease temperature-related deaths in Melbourne, which is a city located in a temperate climate that has warm summers and has been impacted by extreme temperatures. Therefore, the validity of the V-shaped relationship imposed in Martens (1998) is cast in 
greater doubt and this has implications for damage functions built using these relationships in Huber et al. (2017). The difference in these results to previous studies has relevance to the discussion on damage functions. These differences are likely to be related to the use of fixed effects estimation, monthly dummy variables to capture seasonality, and a measure that accounts for acclimatisation. Future research should assess whether finding a Uor V-shaped relationship in other regions occurs using the threshold model specifications applied in this paper. 


\section{CONCLUSION}

Within this paper, fixed effect threshold regressions have been utilised to determine the threshold temperatures that are related with heightened mortality during and after extreme heat events. These thresholds have been computed to display a method for estimating a region-specific temperature-mortality relationship that can be used to develop region-specific damage functions that account for acclimatisation and mortality displacement. This method requires no prior assumption for the shape of the temperature-mortality relationship nor does it require an exogenous threshold to define a heatwave/coldwave event. As there is a limited impact of cold weather on mortality within these estimates, the temperature-mortality relationship estimated is dissimilar to the V-shaped relationship found in Martens (1998) and applied to climate damages in the literature stemming from Tol (2002a). It is also dissimilar to the U-shaped relationship estimated in Gasparrini et al. (2015), Guo et al. (2016) and Gasparrini et al. (2017) for Australian capital cities.

This paper finds that there is little association between coldwaves and mortality for five Australian capital cities that span temperate (with warm summers) and sub-tropical climates. A lower impact of cold weather events is explained by differences in the regression models used. For example, seasonality is accounted for in a different manner, the heat measure used is specified in relation to recent temperatures and a fixed effects model is applied. The major difference is that the temperature-mortality relationship is endogenously determined by the historical relationship in the data rather than an assumed functional form. These results cast doubt on the reductions in mortality associated with future temperatures and climate change that were estimated in Guo et al. (2016) for Melbourne. It should be noted that Melbourne and Adelaide are the major Australian capital cities that have been severely impacted by notable heat-related mortality events in the past.

The results presented in this paper are also notably different to those found in Gasparrini et al. (2015) where the attributable mortality associated with cold temperatures was $6.50 \%$ and $0.45 \%$ for heat. These results were established for Australia using data from three capital cities (i.e. Melbourne, Sydney and Brisbane). In a follow up paper, Gasparrini et al. (2017), the temperature mortality relationships found in Gasparrini et al. (2015) were applied to Global Climate Model (GCM) projections to assess the impact of climate change on mortality. Note 
that Gasparrini et al. (2017) finds a net reduction in deaths due to climate change (even for a high emission RCP 8.5 scenario).

Further applications of this approach and the EHF/EHI_A measures to other regions will assist with the assessment of whether heatwave measures and their trigger thresholds should account for recent temperatures and a lack of acclimatisation. In the interim, the results of this paper suggest that a wider use of heatwave measures that account for acclimatisation and regional differences should be encouraged. Assessments of how a temperature-mortality function that adjusts for mortality displacement and acclimatisation differs across regions and countries will be of direct relevance to damage functions applied within global IAMs. Whether the thresholds that were estimated for Australian capital cities using the EHI_A measure are similar to those that would be estimated using data from other areas (such as Europe and the United States) will be important contributions of future research with great relevance to heatwave emergency response plans, forecasting temperature-related mortality and assessments of the impact of climate change using damage functions or projections from GCMs. 


\section{References}

ABS (2010) 1216.0.55.003 - Australian Statistical Geography Standard: Design of the Statistical Areas Level 4, Capital Cities and Statistical Areas Level 3, May 2010

ABS (2016) Deaths, Australia (cat. no. 3302.0)

ABS (2018) Estimated Residental Population by SA2 (ASGS 2016). ABS Stat

Ackerman F, Stanton EA (2008) A comment on "Economy-wide estimates of the implications of climate change: Human health" Ecological Economics 66:8-13 doi:http://doi.org/10.1016/j.ecolecon.2007.10.006

Allen MJ, Sheridan SC (2018) Mortality risks during extreme temperature events (ETEs) using a distributed lag non-linear model International journal of biometeorology 62:57-67

Analitis A et al. (2008) Effects of Cold Weather on Mortality: Results From 15 European Cities Within the PHEWE Project American Journal of Epidemiology 168:1397-1408 doi:10.1093/aje/kwn266

Anderson BG, Bell ML (2009) Weather-Related Mortality: How Heat, Cold, and Heat Waves Affect Mortality in the United States Epidemiology 20:205-213 doi:10.1097/EDE.0b013e318190ee08

Armstrong B et al. (2017) Longer-Term Impact of High and Low Temperature on Mortality: An International Study to Clarify Length of Mortality Displacement Environmental health perspectives 125:107009

Australian Associated Press (2015) Extreme heat warning for South Australia, with temperatures hitting 42C.

Baccini M et al. (2008) Heat effects on mortality in 15 European cities Epidemiology 19:711-719

Benmarhnia T et al. (2016) A Difference-in-Differences Approach to Assess the Effect of a Heat Action Plan on Heat-Related Mortality, and Differences in Effectiveness According to Sex, Age, and Socioeconomic Status (Montreal, Quebec) Environmental Health Perspectives 124:1694-1699 doi:10.1289/EHP203

BOM (2009) The exceptional January-February 2009 heatwave in south-eastern Australia

Bosello F et al. (2006) Economy-wide estimates of the implications of climate change: Human health Ecological Economics 58:579-591 doi:http://doi.org/10.1016/j.ecolecon.2005.07.032

Bouchama A (2004) The 2003 European heat wave Intensive Care Med 30 doi:10.1007/s00134-0032062-y

Braga ALF et al. (2001) The time course of weather-related deaths Epidemiology 12:662-667

D'Ippoliti D et al. (2010) The impact of heat waves on mortality in 9 European cities: results from the EuroHEAT project Environmental Health 9:37 doi:10.1186/1476-069x-9-37

Dang TN et al. (2016) Characterizing the relationship between temperature and mortality in tropical and subtropical cities: a distributed lag non-linear model analysis in Hue, Viet Nam, 20092013 Global health action 9

Davis RE et al. (2003) Changing heat-related mortality in the United States Environmental health perspectives 111:1712

Díaz J et al. (2015) Comparison of the effects of extreme temperatures on daily mortality in Madrid (Spain), by age group: The need for a cold wave prevention plan Environmental Research 143, Part A:186-191 doi:https://doi.org/10.1016/j.envres.2015.10.018

Gasparrini A et al. (2015) Mortality risk attributable to high and low ambient temperature: a multicountry observational study The Lancet 386:369-375

Gasparrini A et al. (2017) Projections of temperature-related excess mortality under climate change scenarios The Lancet Planetary Health 1:e360-e367 doi:10.1016/S2542-5196(17)30156-0

Gosling SN et al. (2016) Adaptation to climate change: a comparative analysis of modelling methods for heat-related mortality Environmental Health Perspectives

Gosling SN et al. (2009) Associations between elevated atmospheric temperature and human mortality: a critical review of the literature Climatic Change 92:299-341 doi:10.1007/s10584008-9441-x

Gronlund CJ et al. (2016) Vulnerability to renal, heat and respiratory hospitalizations during extreme heat among U.S. elderly Climatic Change 136:631-645 doi:10.1007/s10584-016-1638-9 
Guo Y et al. (2014) Global variation in the effects of ambient temperature on mortality: a systematic evaluation Epidemiology 25:781-789 doi:10.1097/EDE.0000000000000165

Guo Y et al. (2016) Projecting future temperature-related mortality in three largest Australian cities Environmental pollution 208:66-73

Hajat S et al. (2005) Mortality displacement of heat-related deaths: a comparison of Delhi, Sao Paulo, and London Epidemiology 16:613-620

Hansen BE (1999) Threshold effects in non-dynamic panels: Estimation, testing, and inference Journal of econometrics 93:345-368

Hatvani-Kovacs G et al. (2016) Can the Excess Heat Factor indicate heatwave-related morbidity? A case study in Adelaide, South Australia EcoHealth 13:100-110

Huber V et al. (2017) Cold-and heat-related mortality: a cautionary note on current damage functions with net benefits from climate change Climatic Change:1-12

Jegasothy E et al. (2017) Extreme climatic conditions and health service utilisation across rural and metropolitan New South Wales International journal of biometeorology 61:1359-1370

Kaiser R et al. (2007) The effect of the 1995 heat wave in Chicago on all-cause and cause-specific mortality American journal of public health 97:S158-S162

Kinney PL et al. (2008) Approaches for estimating effects of climate change on heat-related deaths: challenges and opportunities Environmental science \& policy 11:87-96

Langlois $\mathrm{N}$ et al. (2013) Using the Excess Heat Factor (EHF) to predict the risk of heat related deaths Journal of forensic and legal medicine 20:408-411

Le Tertre A et al. (2006) Impact of the 2003 heatwave on all-cause mortality in 9 French cities Epidemiology 17:75-79

Loridan T et al. (2016) The Excess Heat Factor as a metric for heat-related fatalities: Defining heatwave risk categories Australian Journal of Emergency Management, The 31:31

Martens WJ (1998) Climate change, thermal stress and mortality changes Social science \& medicine 46:331-344

Medina-Ramón M, Schwartz J (2007) Temperature, temperature extremes, and mortality: a study of acclimatisation and effect modification in 50 US cities Occupational and Environmental Medicine 64:827

Montero JC et al. (2010) Mortality from cold waves in Castile — La Mancha, Spain Science of The Total Environment 408:5768-5774 doi:https://doi.org/10.1016/j.scitotenv.2010.07.086

Nairn J, Fawcett R (2015) The Excess Heat Factor: A Metric for Heatwave Intensity and Its Use in Classifying Heatwave Severity International Journal of Environmental Research and Public Health 12:227

Nairn JR et al. (2013) Defining heatwaves: heatwave defined as a heat-impact event servicing all community and business sectors in Australia. Centre for Australian Weather and Climate Research,

Nitschke M et al. (2016) Evaluation of a heat warning system in Adelaide, South Australia, using case-series analysis BMJ open 6:e012125

Piticar A et al. (2018) Recent changes in heat waves and cold waves detected based on excess heat factor and excess cold factor in Romania International Journal of Climatology 38:1777-1793

Qiao Z et al. (2015) Assessment of short-and long-term mortality displacement in heat-related deaths in Brisbane, Australia, 1996-2004 Environmental health perspectives 123:766

Rocklöv J et al. (2009) Winter mortality modifies the heat-mortality association the following summer European Respiratory Journal 33:245-251

Roson R, Van der Mensbrugghe D (2012) Climate change and economic growth: impacts and interactions International Journal of Sustainable Economy 4:270-285

Saha MV et al. (2013) Mortality Displacement as a Function of Heat Event Strength in 7 US Cities American Journal of Epidemiology 179:467-474 doi:10.1093/aje/kwt264

Scalley BD et al. (2015) Responding to heatwave intensity: Excess Heat Factor is a superior predictor of health service utilisation and a trigger for heatwave plans Australian and New Zealand journal of public health 39:582-587

Smith KR et al. (2014) Human health: impacts, adaptation, and co-benefits. In: Climate Change 2014: Impacts, Adaptation, and Vulnerability Part A: Global and Sectoral Aspects Contribution of 
Working Group II to the Fifth Assessment Report of the Intergovernmental Panel on Climate Change 709-754

Tol RSJ (2002a) Estimates of the Damage Costs of Climate Change. Part I: Benchmark Estimates Environmental and Resource Economics 21:47-73 doi:10.1023/a:1014500930521

Tol RSJ (2002b) Estimates of the Damage Costs of Climate Change, Part II. Dynamic Estimates Environmental and Resource Economics 21:135-160 doi:10.1023/a:1014539414591

Tol RSJ (2013) The economic impact of climate change in the 20th and 21st centuries Climatic Change 117:795-808 doi:10.1007/s10584-012-0613-3

Toulemon L, Barbieri M (2008) The mortality impact of the August 2003 heat wave in France: investigating the 'harvesting'effect and other long-term consequences Population studies 62:39-53

Vict. Dept. of Health (2014) The health impacts of the January 2014 heatwave in Victoria.

Wahlquist C (2015) Melbourne braces for heatwave as temperatures could hit 40C on Saturday.

Wang Q (2015) Fixed-effect panel threshold model using Stata Stata Journal 15:121-134

Wang Y et al. (2016) Estimating and projecting the effect of cold waves on mortality in 209 US cities Environment international 94:141-149

Yardley J et al. (2011) Heat health planning: The importance of social and community factors Global Environmental Change 21:670-679

$\mathrm{Yu} \mathrm{W}$ et al. (2011) Assessing the relationship between global warming and mortality: lag effects of temperature fluctuations by age and mortality categories Environmental pollution 159:17891793 
Table 1 - Summary statistics - Mortality and EHI_A

\begin{tabular}{|c|c|c|c|c|c|c|c|c|c|c|}
\hline \multicolumn{11}{|c|}{ a) Mortality } \\
\hline \multicolumn{2}{|l|}{ Region } & $\min$ & $\begin{array}{c}1^{\text {st }} \\
\text { perc. }\end{array}$ & $\begin{array}{c}5^{\text {th }} \\
\text { perc. }\end{array}$ & $\begin{array}{c}\mathbf{5 0}^{\text {th }} \\
\text { perc. }\end{array}$ & Mean & $\begin{array}{c}9^{\text {th }} \\
\text { perc. }\end{array}$ & $\begin{array}{l}\text { 99th } \\
\text { perc. }\end{array}$ & $\max$ & $\mathbf{N}$ \\
\hline \multicolumn{2}{|l|}{ Sydney } & 15 & 48 & 54 & 71 & 72 & 93 & 103 & 118 & 5417 \\
\hline & East, City and Inner West & 0 & 5 & 6 & 12 & 12 & 19 & 22 & 27 & 5417 \\
\hline & North & 0 & 5 & 8 & 14 & 14 & 21 & 24 & 33 & 5417 \\
\hline & South & 3 & 5 & 7 & 13 & 13 & 20 & 23 & 30 & 5417 \\
\hline & West & 0 & 5 & 7 & 12 & 13 & 20 & 23 & 30 & 5417 \\
\hline & Outer West & 0 & 4 & 6 & 12 & 12 & 19 & 22 & 31 & 5417 \\
\hline & Central Coast & 0 & 3 & 4 & 8 & 8 & 13 & 16 & 20 & 5417 \\
\hline \multicolumn{2}{|l|}{ Melbourne } & 19 & 42 & 48 & 64 & 64 & 81 & 89 & 150 & 5417 \\
\hline & Inner & 3 & 11 & 14 & 22 & 22 & 31 & 35 & 58 & 5417 \\
\hline & North and West & 5 & 9 & 11 & 19 & 19 & 28 & 32 & 76 & 5417 \\
\hline & East and Mornington & 6 & 12 & 15 & 23 & 23 & 33 & 37 & 50 & 5417 \\
\hline \multicolumn{2}{|l|}{ Brisbane } & 5 & 18 & 21 & 31 & 32 & 43 & 49 & 59 & 5417 \\
\hline & Brisbane City & 3 & 9 & 11 & 18 & 18 & 26 & 29 & 39 & 5417 \\
\hline & Ipswich, Logan and Morten Bay & 3 & 5 & 7 & 13 & 14 & 21 & 25 & 35 & 5417 \\
\hline \multicolumn{2}{|l|}{ Adelaide } & 5 & 14 & 17 & 25 & 26 & 35 & 40 & 52 & 5417 \\
\hline & North, Central and Hills & 0 & 5 & 7 & 13 & 13 & 20 & 23 & 29 & 5417 \\
\hline & West and South & 3 & 5 & 7 & 12 & 12 & 19 & 22 & 31 & 5417 \\
\hline \multicolumn{2}{|l|}{ Perth } & 10 & 14 & 17 & 26 & 26 & 37 & 42 & 50 & 5417 \\
\hline & West & 3 & 7 & 9 & 16 & 16 & 24 & 28 & 38 & 5417 \\
\hline & East & 3 & 3 & 5 & 10 & 10 & 16 & 19 & 24 & 5417 \\
\hline \multicolumn{11}{|c|}{ b) Mortality per 100,000 people } \\
\hline \multicolumn{2}{|l|}{ Region } & $\min$ & $\begin{array}{c}1^{\text {st }} \\
\text { perc. }\end{array}$ & $\begin{array}{c}5^{\text {th }} \\
\text { perc. }\end{array}$ & $\begin{array}{c}5^{\text {th }} \\
\text { perc. }\end{array}$ & Mean & $\begin{array}{l}95^{\text {th }} \\
\text { perc. }\end{array}$ & $\begin{array}{l}9^{\text {th }} \\
\text { perc. }\end{array}$ & $\max$ & $\mathbf{N}$ \\
\hline \multicolumn{2}{|l|}{ Sydney } & 0.30 & 1.09 & 1.22 & 1.61 & 2.07 & 2.10 & 2.32 & 2.68 & 5417 \\
\hline & East, City and Inner West & 0.00 & 0.58 & 0.81 & 1.53 & 1.56 & 2.45 & 2.94 & 3.83 & 5417 \\
\hline & North & 0.00 & 0.67 & 0.94 & 1.72 & 1.75 & 2.68 & 3.13 & 4.43 & 5417 \\
\hline & South & 0.37 & 0.68 & 0.96 & 1.70 & 1.76 & 2.67 & 3.09 & 4.22 & 5417 \\
\hline & West & 0.00 & 0.54 & 0.75 & 1.39 & 1.41 & 2.14 & 2.50 & 3.62 & 5417 \\
\hline & Outer West & 0.00 & 0.47 & 0.70 & 1.32 & 1.34 & 2.07 & 2.38 & 3.15 & 5417 \\
\hline & Central Coast & 0.00 & 0.92 & 1.22 & 2.53 & 2.61 & 4.29 & 5.27 & 6.31 & 5417 \\
\hline \multicolumn{2}{|l|}{ Melbourne } & 0.41 & 1.07 & 1.24 & 1.62 & 1.63 & 2.06 & 2.26 & 3.72 & 5417 \\
\hline & Inner & 0.21 & 0.86 & 1.11 & 1.75 & 1.78 & 2.56 & 2.89 & 4.60 & 5417 \\
\hline & North and West & 0.31 & 0.69 & 0.88 & 1.43 & 1.44 & 2.05 & 2.38 & 5.63 & 5417 \\
\hline & East and Mornington & 0.38 & 0.85 & 1.07 & 1.65 & 1.66 & 2.28 & 2.56 & 3.52 & 5417 \\
\hline Brisbane & & 0.22 & 0.91 & 1.07 & 1.56 & 1.58 & 2.13 & 2.41 & 3.01 & 5417 \\
\hline & Brisbane City & 0.24 & 0.79 & 1.00 & 1.63 & 1.65 & 2.37 & 2.72 & 3.92 & 5417 \\
\hline & Ipswich, Logan and Morten Bay & 0.28 & 0.61 & 0.83 & 1.45 & 1.49 & 2.23 & 2.64 & 3.30 & 5417 \\
\hline Adelaide & & 0.38 & 1.13 & 1.39 & 2.07 & 2.09 & 2.87 & 3.27 & 3.96 & 5417 \\
\hline & North, Central and Hills & 0.00 & 0.93 & 1.30 & 2.31 & 2.36 & 3.54 & 4.10 & 5.41 & 5417 \\
\hline & West and South & 0.42 & 0.71 & 1.01 & 1.83 & 1.87 & 2.86 & 3.35 & 4.53 & 5417 \\
\hline Perth & & 0.65 & 0.86 & 1.03 & 1.54 & 1.55 & 2.10 & 2.39 & 3.44 & 5417 \\
\hline & West & 0.35 & 0.74 & 0.98 & 1.65 & 1.67 & 2.44 & 2.79 & 4.54 & 5417 \\
\hline & East & 0.35 & 0.47 & 0.68 & 1.37 & 1.38 & 2.18 & 2.59 & 3.12 & 5417 \\
\hline & c) & Index & Acclim & tisation & EHI_A & & & & & \\
\hline Region & & $\min$ & $\begin{array}{c}1^{\text {st }} \\
\text { perc. }\end{array}$ & $\begin{array}{c}5^{\text {th }} \\
\text { perc. }\end{array}$ & $\begin{array}{c}\mathbf{5 0}^{\text {th }} \\
\text { perc. }\end{array}$ & Mean & $\begin{array}{l}95^{\text {th }} \\
\text { perc. }\end{array}$ & $\begin{array}{c}\text { 99 }^{\text {th }} \\
\text { perc. }\end{array}$ & $\max$ & $\mathbf{N}$ \\
\hline Sydney & & -5.03 & -3.74 & -2.80 & -0.07 & 0.00 & 3.16 & 4.77 & 8.68 & 5417 \\
\hline & East, City and Inner West & -5.03 & -3.74 & -2.80 & -0.07 & 0.00 & 3.16 & 4.77 & 8.68 & 5417 \\
\hline & North & -6.02 & -4.08 & -3.11 & -0.10 & 0.00 & 3.53 & 5.39 & 9.55 & 5417 \\
\hline & South & -5.90 & -4.01 & -3.09 & -0.09 & 0.00 & 3.45 & 4.90 & 7.56 & 5417 \\
\hline & West & -7.58 & -4.14 & -3.17 & -0.11 & 0.00 & 3.59 & 5.28 & 8.47 & 5417 \\
\hline & Outer West & -7.01 & -4.46 & -3.38 & -0.08 & 0.00 & 3.67 & 5.33 & 8.21 & 5417 \\
\hline & Central Coast & -6.03 & -4.07 & -3.07 & -0.10 & 0.00 & 3.41 & 5.08 & 8.16 & 5417 \\
\hline Melbourne & & -7.39 & -4.73 & -3.57 & -0.18 & 0.00 & 4.04 & 6.27 & 12.00 & 5417 \\
\hline & Inner & -7.32 & -5.11 & -3.65 & -0.12 & 0.00 & 3.95 & 6.14 & 12.38 & 5417 \\
\hline & North and West & -7.52 & -4.94 & -3.64 & -0.16 & 0.00 & 4.17 & 6.33 & 12.51 & 5417 \\
\hline & East and Mornington & -6.60 & -4.51 & -3.41 & -0.13 & 0.00 & 3.90 & 6.15 & 11.34 & 5417 \\
\hline Brisbane & & -5.37 & -3.73 & -2.71 & -0.02 & 0.00 & 2.70 & 3.82 & 6.82 & 5417 \\
\hline & Brisbane City & -5.45 & -3.76 & -2.57 & -0.06 & 0.00 & 2.80 & 4.02 & 6.79 & 5417 \\
\hline & Ipswich, Logan and Morten Bay & -6.28 & -4.57 & -3.28 & -0.12 & 0.00 & 3.54 & 5.27 & 8.44 & 5417 \\
\hline Adelaide & & -9.92 & -5.80 & -4.14 & -0.19 & 0.00 & 5.03 & 7.85 & 12.52 & 5417 \\
\hline & North, Central and Hills & -9.91 & -5.85 & -4.28 & -0.15 & 0.00 & 5.02 & 7.89 & 12.11 & 5417 \\
\hline & West and South & -8.99 & -5.28 & -3.74 & -0.19 & 0.00 & 4.39 & 7.37 & 11.68 & 5417 \\
\hline Perth & & -9.90 & -5.53 & -3.99 & 0.00 & -0.01 & 4.06 & 6.23 & 9.61 & 5417 \\
\hline & West & -7.66 & -4.64 & -3.47 & -0.03 & -0.01 & 3.65 & 6.14 & 9.59 & 5417 \\
\hline & East & -8.86 & -5.35 & -3.94 & -0.03 & -0.01 & 4.13 & 6.41 & 10.70 & 5417 \\
\hline
\end{tabular}


Figure 1 - Model estimates of the accumulated sixteen day temperature-related mortality

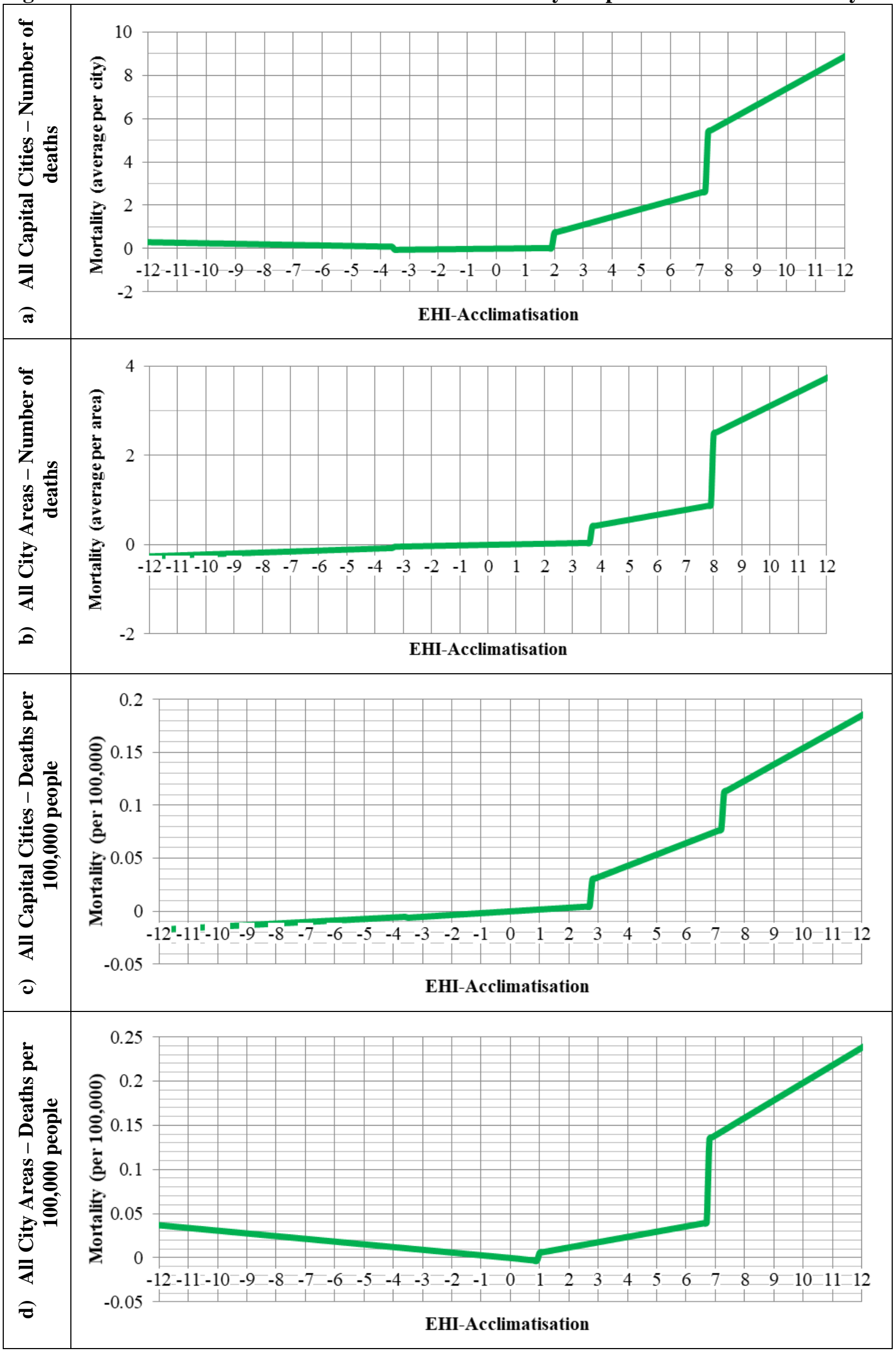


Figure 2 - Annual estimates of short-term displacement adjusted temperature-related mortality

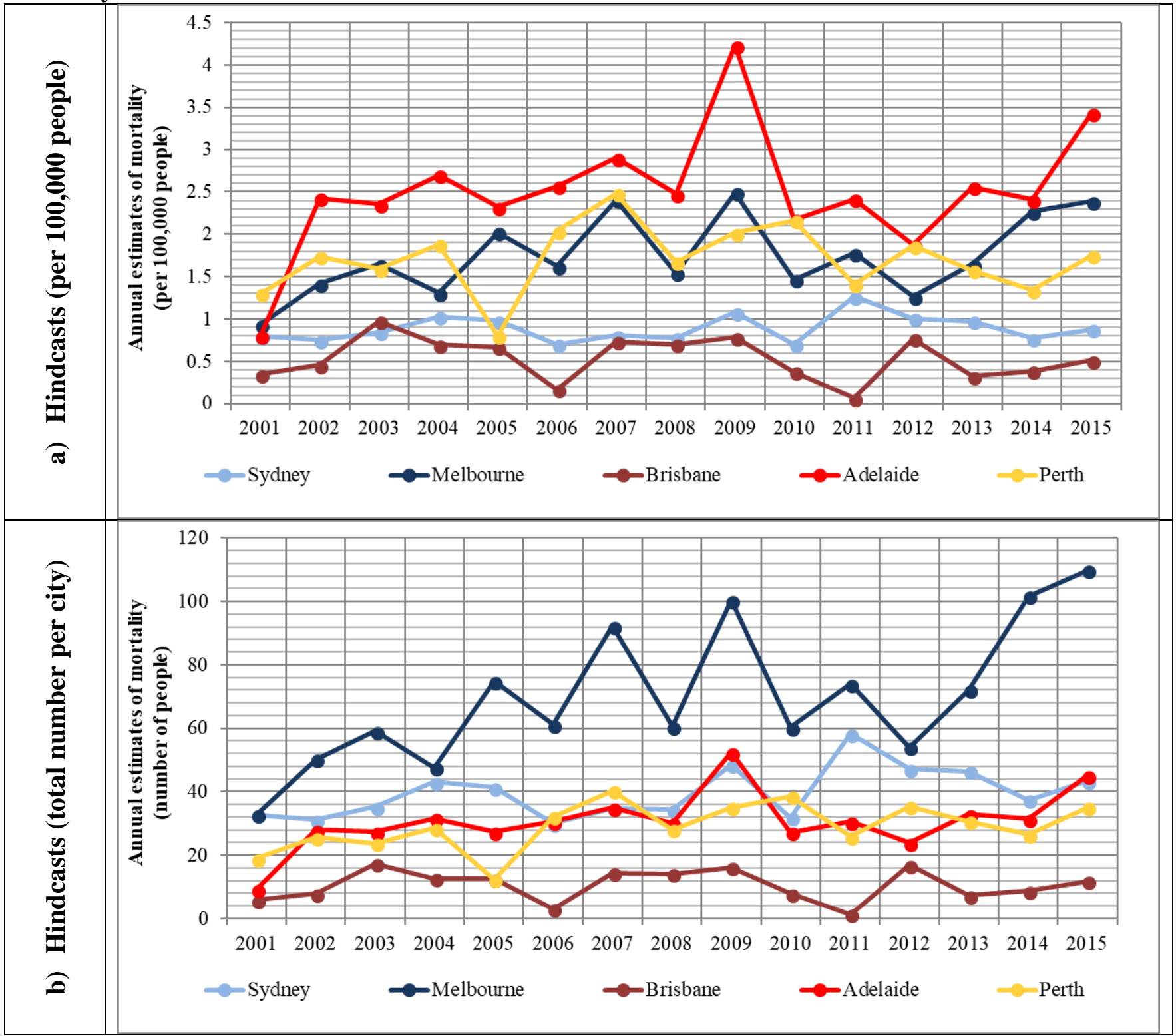


Table 2 - Five yearly hindcasts of short-term displacement adjusted temperature-related mortality between 2001 and 2015 by capital cityand EHI_A threshold

\begin{tabular}{|c|c|c|c|c|c|}
\hline \multirow[b]{2}{*}{ Years } & \multicolumn{5}{|c|}{ Sydney } \\
\hline & $\begin{array}{c}\text { Low/cold } \\
\text { temperatures } \\
\left(<\gamma_{1}\right)\end{array}$ & $\begin{array}{c}\text { Moderate } \\
\text { temperatures } \\
\left(\geq \gamma_{1} \&<\gamma_{2}\right)\end{array}$ & $\begin{array}{l}\text { High heat/hot } \\
\text { temperatures } \\
\left(\geq \gamma_{2} \&<\gamma_{3}\right)\end{array}$ & $\begin{array}{c}\text { Extreme heat } \\
\text { temperatures } \\
\left(\geq \gamma_{3}\right)\end{array}$ & $\begin{array}{c}\text { All } \\
\text { temperatures }\end{array}$ \\
\hline $2001-2005$ & -6 & -47 & 216 & 20 & 183 \\
\hline $2006-2010$ & -8 & -47 & 234 & 0 & 180 \\
\hline $2011-2015$ & -8 & -57 & 286 & 12 & 233 \\
\hline All years & -21 & -151 & 736 & 32 & 596 \\
\hline \multirow[b]{2}{*}{ Years } & \multicolumn{5}{|c|}{ Melbourne } \\
\hline & $\begin{array}{c}\text { Low/cold } \\
\text { temperatures } \\
\left(<\gamma_{1}\right)\end{array}$ & $\begin{array}{c}\text { Moderate } \\
\text { temperatures } \\
\left(\geq \gamma_{1} \&<\gamma_{2}\right)\end{array}$ & $\begin{array}{l}\text { High heat/hot } \\
\text { temperatures } \\
\left(\geq \gamma_{2} \&<\gamma_{3}\right)\end{array}$ & $\begin{array}{c}\text { Extreme heat } \\
\text { temperatures } \\
\left(\geq \gamma_{3}\right)\end{array}$ & $\begin{array}{c}\text { All } \\
\text { temperatures }\end{array}$ \\
\hline $2001-2005$ & -14 & -53 & 327 & 5 & 265 \\
\hline $2006-2010$ & -33 & -49 & 386 & 72 & 375 \\
\hline $2011-2015$ & -24 & -59 & 420 & 75 & 411 \\
\hline All years & -72 & -161 & 1,132 & 151 & 1,051 \\
\hline \multirow[b]{2}{*}{ Years } & \multicolumn{5}{|c|}{ Brisbane } \\
\hline & $\begin{array}{c}\text { Low/cold } \\
\text { temperatures } \\
\left(<\gamma_{1}\right)\end{array}$ & $\begin{array}{c}\text { Moderate } \\
\text { temperatures } \\
\left(\geq \gamma_{1} \&<\gamma_{2}\right)\end{array}$ & $\begin{array}{l}\text { High heat/hot } \\
\text { temperatures } \\
\left(\geq \gamma_{2} \&<\gamma_{3}\right)\end{array}$ & $\begin{array}{c}\text { Extreme heat } \\
\text { temperatures } \\
\quad\left(\geq \gamma_{3}\right)\end{array}$ & $\begin{array}{c}\text { All } \\
\text { temperatures }\end{array}$ \\
\hline $2001-2005$ & -3 & -17 & 76 & 0 & 56 \\
\hline $2006-2010$ & -2 & -19 & 78 & 0 & 56 \\
\hline $2011-2015$ & -4 & -16 & 66 & 0 & 46 \\
\hline All years & -9 & -52 & 220 & 0 & 159 \\
\hline \multirow[b]{2}{*}{ Years } & \multicolumn{5}{|c|}{ Adelaide } \\
\hline & $\begin{array}{c}\text { Low/cold } \\
\text { temperatures } \\
\left(<\gamma_{1}\right)\end{array}$ & $\begin{array}{c}\text { Moderate } \\
\text { temperatures } \\
\left(\geq \gamma_{1} \&<\gamma_{2}\right)\end{array}$ & $\begin{array}{l}\text { High heat/hot } \\
\text { temperatures } \\
\left(\geq \gamma_{2} \&<\gamma_{3}\right)\end{array}$ & $\begin{array}{c}\text { Extreme heat } \\
\text { temperatures } \\
\quad\left(\geq \gamma_{3}\right)\end{array}$ & $\begin{array}{c}\text { All } \\
\text { temperatures }\end{array}$ \\
\hline $2001-2005$ & -9 & -16 & 113 & 36 & 124 \\
\hline $2006-2010$ & -15 & -16 & 140 & 66 & 175 \\
\hline $2011-2015$ & -13 & -17 & 152 & 41 & 164 \\
\hline All years & -37 & -49 & 406 & 144 & 463 \\
\hline \multirow[b]{2}{*}{ Years } & \multicolumn{5}{|c|}{ Perth } \\
\hline & $\begin{array}{c}\text { Low/cold } \\
\text { temperatures } \\
\left(<\gamma_{1}\right)\end{array}$ & $\begin{array}{c}\text { Moderate } \\
\text { temperatures } \\
\left(\geq \gamma_{1} \&<\gamma_{2}\right)\end{array}$ & $\begin{array}{l}\text { High heat/hot } \\
\text { temperatures } \\
\left(\geq \gamma_{2} \&<\gamma_{3}\right)\end{array}$ & $\begin{array}{c}\text { Extreme heat } \\
\text { temperatures } \\
\quad\left(\geq \gamma_{3}\right)\end{array}$ & $\begin{array}{c}\text { All } \\
\text { temperatures }\end{array}$ \\
\hline $2001-2005$ & -14 & -13 & 131 & 6 & 109 \\
\hline $2006-2010$ & -15 & -17 & 167 & 39 & 174 \\
\hline $2011-2015$ & -15 & -21 & 180 & 9 & 154 \\
\hline All years & -43 & -52 & 478 & 54 & 437 \\
\hline
\end{tabular}




\section{Appendix}

Table 1A - Specification and summary statistics of the explanatory variables in the threshold models

\begin{tabular}{|c|c|c|c|c|c|c|c|c|c|c|c|}
\hline Type of Variable & $\begin{array}{l}\text { Variable } \\
\text { description }\end{array}$ & Variable Type & $\min$ & $\begin{array}{c}1^{\text {st }} \\
\text { perc. }\end{array}$ & $\begin{array}{c}5^{\text {th }} \\
\text { perc. }\end{array}$ & $\begin{array}{l}\mathbf{5 0}^{\text {th }} \\
\text { perc. }\end{array}$ & Mean & $\begin{array}{l}95^{\text {th }} \\
\text { perc. }\end{array}$ & $\begin{array}{l}99^{\text {th }} \\
\text { perc. }\end{array}$ & $\max$ & $\mathbf{N}$ \\
\hline \multirow{6}{*}{ Days of the week } & Monday & DV & 0.00 & 0.00 & 0.00 & 0.00 & 0.14 & 1.00 & 1.00 & 1.00 & 27085 \\
\hline & Tuesday & DV & 0.00 & 0.00 & 0.00 & 0.00 & 0.14 & 1.00 & 1.00 & 1.00 & 27085 \\
\hline & Thursday & DV & 0.00 & 0.00 & 0.00 & 0.00 & 0.14 & 1.00 & 1.00 & 1.00 & 27085 \\
\hline & Friday & DV & 0.00 & 0.00 & 0.00 & 0.00 & 0.14 & 1.00 & 1.00 & 1.00 & 27085 \\
\hline & Saturday & DV & 0.00 & 0.00 & 0.00 & 0.00 & 0.14 & 1.00 & 1.00 & 1.00 & 27085 \\
\hline & Sunday & DV & 0.00 & 0.00 & 0.00 & 0.00 & 0.14 & 1.00 & 1.00 & 1.00 & 27085 \\
\hline \multirow{11}{*}{ Months } & January & DV & 0.00 & 0.00 & 0.00 & 0.00 & 0.08 & 1.00 & 1.00 & 1.00 & 27085 \\
\hline & February & DV & 0.00 & 0.00 & 0.00 & 0.00 & 0.08 & 1.00 & 1.00 & 1.00 & 27085 \\
\hline & March & DV & 0.00 & 0.00 & 0.00 & 0.00 & 0.08 & 1.00 & 1.00 & 1.00 & 27085 \\
\hline & April & DV & 0.00 & 0.00 & 0.00 & 0.00 & 0.08 & 1.00 & 1.00 & 1.00 & 27085 \\
\hline & June & DV & 0.00 & 0.00 & 0.00 & 0.00 & 0.08 & 1.00 & 1.00 & 1.00 & 27085 \\
\hline & July & DV & 0.00 & 0.00 & 0.00 & 0.00 & 0.08 & 1.00 & 1.00 & 1.00 & 27085 \\
\hline & August & DV & 0.00 & 0.00 & 0.00 & 0.00 & 0.08 & 1.00 & 1.00 & 1.00 & 27085 \\
\hline & September & DV & 0.00 & 0.00 & 0.00 & 0.00 & 0.08 & 1.00 & 1.00 & 1.00 & 27085 \\
\hline & October & DV & 0.00 & 0.00 & 0.00 & 0.00 & 0.08 & 1.00 & 1.00 & 1.00 & 27085 \\
\hline & November & DV & 0.00 & 0.00 & 0.00 & 0.00 & 0.08 & 1.00 & 1.00 & 1.00 & 27085 \\
\hline & December & DV & 0.00 & 0.00 & 0.00 & 0.00 & 0.08 & 1.00 & 1.00 & 1.00 & 27085 \\
\hline \multirow{14}{*}{ Years } & Year 2001 & DV & 0.00 & 0.00 & 0.00 & 0.00 & 0.07 & 1.00 & 1.00 & 1.00 & 27085 \\
\hline & Year 2002 & DV & 0.00 & 0.00 & 0.00 & 0.00 & 0.07 & 1.00 & 1.00 & 1.00 & 27085 \\
\hline & Year 2003 & DV & 0.00 & 0.00 & 0.00 & 0.00 & 0.07 & 1.00 & 1.00 & 1.00 & 27085 \\
\hline & Year 2004 & DV & 0.00 & 0.00 & 0.00 & 0.00 & 0.07 & 1.00 & 1.00 & 1.00 & 27085 \\
\hline & Year 2005 & DV & 0.00 & 0.00 & 0.00 & 0.00 & 0.07 & 1.00 & 1.00 & 1.00 & 27085 \\
\hline & Year 2006 & DV & 0.00 & 0.00 & 0.00 & 0.00 & 0.07 & 1.00 & 1.00 & 1.00 & 27085 \\
\hline & Year 2007 & DV & 0.00 & 0.00 & 0.00 & 0.00 & 0.07 & 1.00 & 1.00 & 1.00 & 27085 \\
\hline & Year 2008 & DV & 0.00 & 0.00 & 0.00 & 0.00 & 0.07 & 1.00 & 1.00 & 1.00 & 27085 \\
\hline & Year 2009 & DV & 0.00 & 0.00 & 0.00 & 0.00 & 0.07 & 1.00 & 1.00 & 1.00 & 27085 \\
\hline & Year 2010 & DV & 0.00 & 0.00 & 0.00 & 0.00 & 0.07 & 1.00 & 1.00 & 1.00 & 27085 \\
\hline & Year 2011 & DV & 0.00 & 0.00 & 0.00 & 0.00 & 0.07 & 1.00 & 1.00 & 1.00 & 27085 \\
\hline & Year 2012 & DV & 0.00 & 0.00 & 0.00 & 0.00 & 0.07 & 1.00 & 1.00 & 1.00 & 27085 \\
\hline & Year 2013 & DV & 0.00 & 0.00 & 0.00 & 0.00 & 0.07 & 1.00 & 1.00 & 1.00 & 27085 \\
\hline & Year 2014 & DV & 0.00 & 0.00 & 0.00 & 0.00 & 0.07 & 1.00 & 1.00 & 1.00 & 27085 \\
\hline $\begin{array}{l}\text { Elderly } \\
\text { population }\end{array}$ & Population $>75$ & $\%$ & 5.09 & 5.09 & 5.10 & 5.86 & 6.18 & 7.58 & 7.60 & 7.60 & 27085 \\
\hline \multirow{2}{*}{$\begin{array}{l}\text { Days with low } \\
\text { mortality }\end{array}$} & Low & DV & 0.00 & 0.00 & 0.00 & 0.00 & 0.02 & 0.00 & 0.00 & 1.00 & 27085 \\
\hline & Very low & DV & 0.00 & 0.00 & 0.00 & 0.00 & 0.00 & 0.00 & 0.00 & 1.00 & 27085 \\
\hline $\begin{array}{l}\text { Extreme heat } \\
\text { measure }\end{array}$ & $\begin{array}{l}\text { Excess Heat } \\
\text { Index - } \\
\text { Acclimatisation }\end{array}$ & $\begin{array}{l}{ }^{\circ} \mathrm{C}(3 \text { day average } \\
\text { temperature / } 30 \text { day } \\
\text { average temperature })\end{array}$ & -9.92 & -5.03 & -3.47 & -0.08 & -0.00 & 3.79 & 6.25 & 12.52 & 27085 \\
\hline
\end{tabular}


Table 2A - Mapping of ABS mortality data and BOM weather stations

\begin{tabular}{|c|c|c|c|c|}
\hline \multicolumn{2}{|l|}{ Region } & \multirow{2}{*}{$\begin{array}{l}\text { Greater Capital City } \\
\text { Statistical Division } \\
\text { 1GSYD Greater Sydney } \\
\end{array}$} & \multirow[t]{2}{*}{ Statistical Area (Level 4) } & \multirow{2}{*}{$\begin{array}{l}\text { BOM Weather Station } \\
66062 \text { - Observatory Hill }\end{array}$} \\
\hline Sydney & & & & \\
\hline & East, City and Inner West & & $\begin{array}{l}117 \text { Sydney - City and Inner South; } 118 \text { Sydney - Eastern } \\
\text { Suburbs; } 120 \text { Sydney - Inner West; }\end{array}$ & 66062 - Observatory Hill \\
\hline & North & & $\begin{array}{l}121 \text { Sydney - North Sydney and Hornsby; } 122 \text { Sydney - Northern } \\
\text { Beaches; } 126 \text { Sydney - Ryde; }\end{array}$ & $\begin{array}{l}\text { 66131 - Lane Cove; } 66059 \text { - Terrey Hills } \\
\text { AWS }\end{array}$ \\
\hline & South & & 119 Sydney - Inner South West; 128 Sydney - Sutherland & 66194 - Canterbury \\
\hline & West & & $\begin{array}{l}115 \text { Sydney - Baulkham Hills and Hawkesbury; } 116 \text { Sydney - } \\
\text { Blacktown; } 125 \text { Sydney - Parramatta }\end{array}$ & 67019 - Prospect Dam \\
\hline & Outer West & & $\begin{array}{l}127 \text { Sydney - South West; } 123 \text { Sydney - Outer South West; } 124 \\
\text { Sydney - Outer West and Blue Mountains }\end{array}$ & 68192 - Camden \\
\hline & Central Coast & & 102 Central Coast & 61087 - Gosford; 61425 - Gosford AWS \\
\hline \multirow[t]{4}{*}{ Melbourne } & & 2GMEL Greater Melbourne & & 87031 - Laverton RAAF \\
\hline & Inner & & $\begin{array}{l}206 \text { Melbourne - Inner; } 207 \text { Melbourne - Inner East; } 208 \\
\text { Melbourne - Inner South }\end{array}$ & 86068 - Viewbank \\
\hline & North and West & & $\begin{array}{l}209 \text { Melbourne - North East; } 210 \text { Melbourne - North West; } 213 \\
\text { Melbourne - West }\end{array}$ & 86282 - Melbourne Airport \\
\hline & East and Mornington & & $\begin{array}{l}211 \text { Melbourne - Outer East; } 212 \text { Melbourne - South East; } 214 \\
\text { Mornington Peninsula }\end{array}$ & 86375 - Cranbourne Botanic Gardens \\
\hline \multirow[t]{3}{*}{ Brisbane } & & 3GBRI Greater Brisbane & & 40842 - Brisbane Airport \\
\hline & Brisbane City & & $\begin{array}{l}301 \text { Brisbane - East; } 302 \text { Brisbane - North; } 303 \text { Brisbane - South; } \\
304 \text { Brisbane - West; } 305 \text { Brisbane Inner City }\end{array}$ & 40913 - Brisbane \\
\hline & Ipswich, Logan and Morten Bay & & $\begin{array}{l}310 \text { Ipswich; } 311 \text { Logan - Beaudesert; } 313 \text { Moreton Bay - North; } \\
314 \text { Moreton Bay - South }\end{array}$ & 40004 - Amberley AMO \\
\hline \multirow[t]{3}{*}{ Adelaide } & & 4GADE Greater Adelaide & & 23090 - Adelaide (Kent Town) \\
\hline & North, Central and Hills & & 403 Adelaide - South; 404 Adelaide - West & 23034 - Adelaide Airport \\
\hline & West and South & & 401 Adelaide - Central and Hills; 402 Adelaide - North & 23013 - Parafield Airport \\
\hline \multirow[t]{3}{*}{ Perth } & & 5GPER Greater Perth & & 9021 - Perth Airport \\
\hline & West & & 503 Perth - Inner; 505 Perth - North West; 507 Perth - South West & 9215 - Swanbourne \\
\hline & East & & 502 Mandurah; 504 Perth - North East; 506 Perth - South East & 9106 - Gosnells City \\
\hline
\end{tabular}


Table 3A - Goodness of fit and threshold statistics from the different threshold models

\begin{tabular}{|c|c|c|c|c|c|}
\hline $\begin{array}{l}\text { Dependent } \\
\text { variable }\end{array}$ & Region & $\begin{array}{l}\text { Number of } \\
\text { thresholds }\end{array}$ & AIC & $\begin{array}{l}\text { Threshold } \\
\text { effect F-test }\end{array}$ & $\begin{array}{l}\text { Estimation } \\
\text { results } \\
\text { shown in: }\end{array}$ \\
\hline \multirow{8}{*}{ 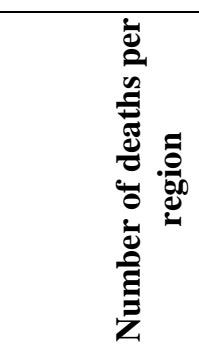 } & \multirow{4}{*}{$\begin{array}{l}\text { All Capital } \\
\text { Cities }\end{array}$} & 1 & 185133.60 & $65.48 * *$ & \\
\hline & & 2 & 185097.90 & $54.31 * * *$ & \\
\hline & & 3 & 185091.70 & 30.48 & Table 4A \\
\hline & & 3 (6 lags of EHI_A) & 185370.10 & 21.54 & Table 6A \\
\hline & \multirow{4}{*}{ All City Areas } & 1 & 446351.00 & $94.01 * * *$ & \\
\hline & & 2 & 446340.00 & $40.50 *$ & \\
\hline & & 3 & 446336.00 & 34.06 & Table 4A \\
\hline & & 3 (6 lags of EHI_A) & 447078.30 & 22.23 & Table 6A \\
\hline \multirow{8}{*}{ 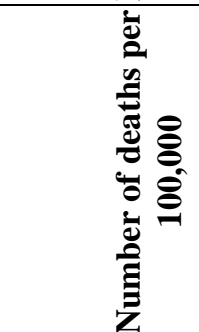 } & \multirow{4}{*}{$\begin{array}{l}\text { All Capital } \\
\text { Cities }\end{array}$} & 1 & 11806.91 & $231.75^{* * *}$ & \\
\hline & & 2 & 11803.76 & $233.31 * * *$ & \\
\hline & & 3 & 11804.05 & $232.03 * * *$ & Table 5A \\
\hline & & 3 (6 lags of EHI_A) & 11798.59 & 13.23 & Table 7A \\
\hline & \multirow{4}{*}{ All City Areas } & 1 & 106701.80 & $1415.68 * * *$ & \\
\hline & & 2 & 106697.10 & $1415.88 * * *$ & \\
\hline & & 3 & 106699.50 & $1415.24 * * *$ & Table 5A \\
\hline & & 3 (6 lags of EHI_A) & 106861.00 & 13.00 & Table 7A \\
\hline
\end{tabular}

Note: The Threshold effect $\mathrm{F}$-test is run sequentially for each threshold. The null hypothesis is whether a lesser number of thresholds is appropriate. For the three threshold model, the null is whether a model with less than three thresholds is appropriate versus the alternative hypothesis of a three threshold model being appropriate. While the Threshold effect $\mathrm{F}$-test indicates that either two or three thresholds are preferred to one threshold, the AIC statistics indicate that three threshold model produced the better model fit. Statistical Significance is indicated as: $* * *$ for $\mathbf{p}<0.01, * *$ for $\mathbf{p}<0.05, *$ for $\mathbf{p}<0.1$. 
Table 4A - Threshold regression model results - Number of deaths per region

\begin{tabular}{|c|c|c|c|c|c|c|c|c|c|c|}
\hline \multirow{2}{*}{ Variables } & \multicolumn{2}{|c|}{ All Capital Cities } & \multicolumn{2}{|c|}{ All City Areas } & \multirow{2}{*}{ Variables } & \multirow{2}{*}{$\begin{array}{c}\text { No. of } \\
\text { lags }\end{array}$} & \multicolumn{2}{|c|}{ All Capital Cities } & \multicolumn{2}{|c|}{ All City Areas } \\
\hline & Coef. & SE & Coef. & SE & & & Coef. & SE & Coef. & SE \\
\hline Constant & $30.59 * * *$ & 4.789 & $3.612 * * *$ & 0.452 & EHI-A $<\gamma_{1}$ & \multirow{4}{*}{0} & $0.538^{*}$ & 0.319 & $0.200 * *$ & 0.0957 \\
\hline Monday & $-0.663 * * *$ & 0.168 & $-0.199 * * *$ & 0.0496 & EHI-A $\geq \gamma_{1} \&<\gamma_{2}$ & & 0.103 & 0.0841 & $0.0497 * *$ & 0.0211 \\
\hline Tuesday & $-0.292^{*}$ & 0.168 & -0.0635 & 0.0495 & EHI-A $\geq \gamma_{2} \&<\gamma_{3}$ & & 0.0512 & 0.124 & -0.0722 & 0.0554 \\
\hline Thursday & 0.231 & 0.168 & 0.0623 & 0.0495 & EHI-A $\geq \gamma_{3}$ & & -0.733 & 0.583 & $-0.489 *$ & 0.291 \\
\hline Friday & $0.859 * * *$ & 0.168 & $0.251 * * *$ & 0.0496 & EHI-A $<\gamma_{1}$ & & -0.810 & 0.582 & -0.198 & 0.171 \\
\hline Saturday & $0.519 * * *$ & 0.168 & $0.173 * * *$ & 0.0496 & EHI-A $\geq \gamma_{1} \&<\gamma_{2}$ & - & $0.299 * *$ & 0.139 & $0.0685^{*}$ & 0.0352 \\
\hline Sunday & $-0.624 * * *$ & 0.168 & $-0.196^{* * * *}$ & 0.0496 & EHI-A $\geq \gamma_{2} \&<\gamma_{3}$ & 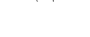 & 0.270 & 0.229 & 0.156 & 0.105 \\
\hline January & $-3.854 * * *$ & 0.246 & $-1.261 * * *$ & 0.0733 & EHI-A $\geq \gamma_{3}$ & & $-2.163^{*}$ & 1.190 & -0.628 & 0.619 \\
\hline February & $-4.078 * * *$ & 0.236 & $-1.345 * * *$ & 0.0698 & EHI-A $<\gamma_{1}$ & & -0.0141 & 0.574 & -0.00951 & 0.164 \\
\hline March & $-3.729 * * *$ & 0.220 & $-1.221 * * *$ & 0.0650 & EHI-A $\geq \gamma_{1} \&<\gamma_{2}$ & & 0.0174 & 0.141 & 0.0458 & 0.0355 \\
\hline April & $-2.586 * * *$ & 0.218 & $-0.860 * * *$ & 0.0645 & EHI-A $\geq \gamma_{2} \&<\gamma_{3}$ & $\sqrt{2}$ & 0.471 ** & 0.240 & 0.0107 & 0.114 \\
\hline June & $2.733 * * *$ & 0.219 & $0.865^{* * *}$ & 0.0648 & EHI-A $\geq \gamma_{3}$ & & $6.731 * * *$ & 1.370 & $2.547 * * *$ & 0.686 \\
\hline July & $5.191 * * *$ & 0.223 & $1.636^{* * * *}$ & 0.0660 & EHI-A $<\gamma_{1}$ & & $1.249 * *$ & 0.626 & 0.271 & 0.181 \\
\hline August & $5.244 * * *$ & 0.236 & $1.655^{* * *}$ & 0.0703 & EHI-A $\geq \gamma_{1} \&<\gamma_{2}$ & $m$ & $-0.431 * * *$ & 0.160 & $-0.120^{* * *}$ & 0.0408 \\
\hline September & $2.483 * * *$ & 0.249 & $0.820 * * *$ & 0.0754 & EHI-A $\geq \gamma_{2} \&<\gamma_{3}$ & 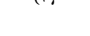 & -0.336 & 0.293 & 0.128 & 0.143 \\
\hline October & -0.360 & 0.246 & $-0.128 *$ & 0.0739 & EHI-A $\geq \gamma_{3}$ & & $-2.863^{*}$ & 1.717 & -0.685 & 0.765 \\
\hline November & $-2.331 * * *$ & 0.251 & $-0.758 * * *$ & 0.0749 & EHI-A $<\gamma_{1}$ & & $-2.086^{* * * *}$ & 0.699 & $-0.494 * *$ & 0.205 \\
\hline December & $-3.228 * * *$ & 0.243 & $-1.058 * * *$ & 0.0725 & EHI-A $\geq \gamma_{1} \&<\gamma_{2}$ & + & 0.137 & 0.181 & -0.000114 & 0.0458 \\
\hline Year 2001 & $-5.428 * * *$ & 0.419 & $-1.077 * * *$ & 0.0827 & EHI-A $\geq \gamma_{2} \&<\gamma_{3}$ & 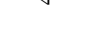 & -0.395 & 0.340 & -0.0904 & 0.161 \\
\hline Year 2002 & $-4.550 * * *$ & 0.357 & $-0.926 * * *$ & 0.0778 & EHI-A $\geq \gamma_{3}$ & & -2.250 & 1.897 & $-1.998 * *$ & 0.930 \\
\hline Year 2003 & $-5.323 * * *$ & 0.312 & $-1.266 * * *$ & 0.0758 & EHI-A $<\gamma_{1}$ & & 0.911 & 0.699 & 0.117 & 0.198 \\
\hline Year 2004 & $-5.566 * * *$ & 0.278 & $-1.425 * * *$ & 0.0744 & EHI-A $\geq \gamma_{1} \&<\gamma_{2}$ & 1 & 0.118 & 0.180 & 0.0673 & 0.0458 \\
\hline Year 2005 & $-5.999 * * *$ & 0.258 & $-1.672 * * *$ & 0.0735 & EHI-A $\geq \gamma_{2} \&<\gamma_{3}$ & 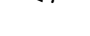 & $0.598^{*}$ & 0.343 & -0.215 & 0.165 \\
\hline Year 2006 & $-5.219 * * *$ & 0.251 & $-1.454 * * *$ & 0.0732 & EHI-A $\geq \gamma_{3}$ & & 2.364 & 2.089 & $2.155 * *$ & 0.918 \\
\hline Year 2007 & $-3.752 * * *$ & 0.252 & $-0.993 * * *$ & 0.0732 & EHI-A $<\gamma_{1}$ & & $1.272 *$ & 0.699 & $0.549 * * *$ & 0.204 \\
\hline Year 2008 & $-2.804 * * *$ & 0.258 & $-0.722 * * *$ & 0.0735 & EHI-A $\geq \gamma_{1} \&<\gamma_{2}$ & 0 & -0.222 & 0.187 & $-0.0866^{*}$ & 0.0478 \\
\hline Year 2009 & $-3.188 * * *$ & 0.271 & $-0.776 * * *$ & 0.0739 & EHI-A $\geq \gamma_{2} \&<\gamma_{3}$ & 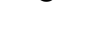 & -0.186 & 0.365 & $0.368 * *$ & 0.172 \\
\hline Year 2010 & $-2.760 * * *$ & 0.268 & $-0.685 * * *$ & 0.0736 & EHI-A $\geq \gamma_{3}$ & & -0.683 & 2.176 & -0.769 & 0.938 \\
\hline Year 2011 & $-1.728 * * *$ & 0.261 & $-0.401 * * *$ & 0.0733 & EHI-A $<\gamma_{1}$ & & $-1.960 * * *$ & 0.723 & $-0.693^{* * *}$ & 0.212 \\
\hline Year 2012 & $-1.222 * * *$ & 0.262 & $-0.284 * * *$ & 0.0733 & EHI-A $\geq \gamma_{1} \&<\gamma_{2}$ & -1 & 0.0899 & 0.190 & -0.00200 & 0.0486 \\
\hline Year 2013 & $-1.220 * * *$ & 0.259 & $-0.317 * * *$ & 0.0731 & EHI-A $\geq \gamma_{2} \&<\gamma_{3}$ & 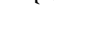 & -0.457 & 0.375 & -0.116 & 0.174 \\
\hline Year 2014 & 0.240 & 0.250 & 0.105 & 0.0729 & EHI-A $\geq \gamma_{3}$ & & -0.328 & 2.008 & -0.205 & 1.109 \\
\hline Population >75 & $2.805 * * *$ & 0.778 & $1.952 * * *$ & 0.0694 & EHI-A $<\gamma_{1}$ & & 0.539 & 0.728 & 0.173 & 0.203 \\
\hline Low mortality & $-16.74 * * *$ & 0.918 & $-7.284 * * *$ & 0.0811 & EHI-A $\geq \gamma_{1} \&<\gamma_{2}$ & $\infty$ & 0.0527 & 0.189 & 0.0774 & 0.0486 \\
\hline VLow mortality & $-37.61 * * *$ & 4.264 & $-10.21 * * *$ & 0.446 & EHI-A $\geq \gamma_{2} \&<\gamma_{3}$ & 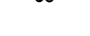 & 0.505 & 0.379 & -0.290 & 0.180 \\
\hline & & & & & EHI-A $\geq \gamma_{3}$ & & 0.627 & 2.316 & 0.377 & 1.099 \\
\hline & & & & & EHI-A $<\gamma_{1}$ & & $1.534 * *$ & 0.712 & 0.251 & 0.198 \\
\hline & & & & & EHI-A $\geq \gamma_{1} \&<\gamma_{2}$ & $a$ & -0.207 & 0.185 & $-0.0879 *$ & 0.0477 \\
\hline & & & & & EHI-A $\geq \gamma_{2} \&<\gamma_{3}$ & & -0.152 & 0.370 & $0.308 *$ & 0.176 \\
\hline & & & & & EHI-A $\geq \gamma_{3}$ & & 1.932 & 2.246 & $1.678^{*}$ & 1.008 \\
\hline & & & & & EHI-A $<\gamma_{1}$ & & $-1.753 * *$ & 0.683 & -0.0747 & 0.196 \\
\hline & & & & & EHI-A $\geq \gamma_{1} \&<\gamma_{2}$ & 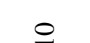 & 0.247 & 0.178 & 0.0201 & 0.0457 \\
\hline & & & & & EHI-A $\geq \gamma_{2} \&<\gamma_{3}$ & $=$ & -0.402 & 0.361 & -0.0287 & 0.169 \\
\hline & & & & & EHI-A $\geq \gamma_{3}$ & & -2.719 & 1.796 & $-2.157 * *$ & 0.968 \\
\hline & & & & & EHI-A $<\gamma_{1}$ & & 0.268 & 0.698 & -0.137 & 0.195 \\
\hline & & & & & EHI-A $\geq \gamma_{1} \&<\gamma_{2}$ & & -0.0543 & 0.177 & 0.0430 & 0.0457 \\
\hline Tempe & ure threshol & s-All & apital Cities & & EHI-A $\geq \gamma_{2} \&<\gamma_{3}$ & - & 0.438 & 0.360 & -0.166 & 0.173 \\
\hline & HI-A $\left(1^{\text {st }} \mathrm{Th}\right.$ & esh.) $=$ & 3.51 & & EHI-A $\geq \gamma_{3}$ & & -1.529 & 1.906 & -1.034 & 0.950 \\
\hline & HI-A $\left(2^{\text {nd }} T\right.$ & esh.) $=$ & & & EHI-A $<\gamma_{1}$ & & 0.646 & 0.619 & 0.129 & 0.173 \\
\hline & HI-A $\left(3^{\text {rd }} T\right.$ & esh.) $=$ & .26 & & EHI-A $\geq \gamma_{1} \&<\gamma_{2}$ & $d$ & -0.226 & 0.157 & $-0.0762^{*}$ & 0.0406 \\
\hline & & & & & EHI-A $\geq \gamma_{2} \&<\gamma_{3}$ & - & 0.120 & 0.311 & 0.162 & 0.150 \\
\hline Temp & ature thresh & $\overline{\mathrm{ds}-\mathrm{Al}}$ & City Areas & & EHI-A $\geq \gamma_{3}$ & & $4.002 * *$ & 1.668 & $2.772 * * *$ & 0.800 \\
\hline & HI-A $\left(1^{\text {st }} \mathrm{Th}\right.$ & esh.) $=$ & 3.36 & & EHI-A $<\gamma_{1}$ & & -0.293 & 0.525 & 0.00813 & 0.149 \\
\hline & HI-A $\left(2^{\text {nd }} T\right.$ & esh. $)=$ & & & EHI-A $\geq \gamma_{1} \&<\gamma_{2}$ & m & 0.197 & 0.137 & 0.0326 & 0.0352 \\
\hline & HI-A $\left(3^{\text {rd }} T\right.$ & esh.) $=$ & & & EHI-A $\geq \gamma_{2} \&<\gamma_{3}$ & - & -0.190 & 0.269 & 0.0958 & 0.130 \\
\hline & & & & & EHI-A $\geq \gamma_{3}$ & & -1.100 & 1.430 & -1.065 & 0.680 \\
\hline & & & & & EHI-A $<\gamma_{1}$ & & -0.200 & 0.489 & -0.0702 & 0.138 \\
\hline & & & & & EHI-A $\geq \gamma_{1} \&<\gamma_{2}$ & f & 0.0296 & 0.134 & 0.0283 & 0.0349 \\
\hline & & & & & EHI-A $\geq \gamma_{2} \&<\gamma_{3}$ & - & -0.118 & 0.266 & -0.176 & 0.130 \\
\hline & & & & & EHI-A $\geq \gamma_{3}$ & & $-2.899 *$ & 1.493 & $-1.524 * *$ & 0.682 \\
\hline & & & & & EHI-A $<\gamma_{1}$ & & 0.137 & 0.255 & -0.00102 & 0.0742 \\
\hline & & & & & EHI-A $\geq \gamma_{1} \&<\gamma_{2}$ & (n) & $-0.135 *$ & 0.0756 & $-0.0471 * *$ & 0.0201 \\
\hline & & & & & EHI-A $\geq \gamma_{2} \&<\gamma_{3}$ & - & 0.151 & 0.150 & 0.0384 & 0.0742 \\
\hline & & & & & EHI-A $\geq \gamma_{3}$ & & $2.350 * * *$ & 0.815 & $1.336 * * *$ & 0.402 \\
\hline & & & & & Observations & & 27,0 & & 81,2 & \\
\hline & & & & & R-squared (within) & & 0.2. & & 0.2 & \\
\hline & & & & & R-squared (between) & & 0.02 & & 0.0 & \\
\hline & & & & & F stat & & 91.60 & & 207.7 & \\
\hline & & & & & Number of groups & & 5 & & 15 & \\
\hline
\end{tabular}

Note: Variables for Wednesday, May and the Year 2015 are not included and absorbed into the constant. Statistical Significance is indicated as: $* * *$ for $\mathrm{p}<0.01, * *$ for $\mathrm{p}<0.05, *$ for $\mathrm{p}<0.1$. 
Table 5A - Threshold regression model results - Number of deaths per 100,000

\begin{tabular}{|c|c|c|c|c|c|c|c|c|c|c|}
\hline \multirow{2}{*}{ Variables } & \multicolumn{2}{|c|}{ All Capital Cities } & \multicolumn{2}{|c|}{ All City Areas } & \multirow{2}{*}{ Variables } & \multirow{2}{*}{$\begin{array}{l}\text { No. of } \\
\text { lags }\end{array}$} & \multicolumn{2}{|c|}{ All Capital Cities } & \multicolumn{2}{|c|}{ All City Areas } \\
\hline & Coef. & SE & Coef. & SE & & & Coef. & SE & Coef. & SE \\
\hline Constant & $1.303^{* * *}$ & 0.195 & $0.223 * * *$ & 0.056 & EHI-A $<\gamma_{1}$ & \multirow{4}{*}{0} & $0.031 * *$ & 0.013 & 0.005 & 0.004 \\
\hline Monday & $-0.027 * * *$ & 0.007 & $-0.022 * * *$ & 0.006 & EHI-A $\geq \gamma_{1} \&<\gamma_{2}$ & & 0.004 & 0.003 & 0.001 & 0.010 \\
\hline Tuesday & -0.009 & 0.007 & -0.010 & 0.006 & EHI-A $\geq \gamma_{2} \&<\gamma_{3}$ & & 0.000 & 0.006 & 0.002 & 0.004 \\
\hline Thursday & $0.011 *$ & 0.007 & 0.007 & 0.006 & EHI-A $\geq \gamma_{3}$ & & -0.023 & 0.024 & -0.025 & 0.020 \\
\hline Friday & $0.031 * * *$ & 0.007 & $0.029 * * *$ & 0.006 & EHI-A $<\gamma_{1}$ & & -0.033 & 0.024 & 0.004 & 0.006 \\
\hline Saturday & $0.023 * * *$ & 0.007 & $0.020 * * *$ & 0.006 & EHI-A $\geq \gamma_{1} \&<\gamma_{2}$ & - & $0.018 * * *$ & 0.005 & 0.012 & 0.012 \\
\hline Sunday & $-0.017 * *$ & 0.007 & $-0.021 * * *$ & 0.006 & EHI-A $\geq \gamma_{2} \&<\gamma_{3}$ & & 0.002 & 0.011 & 0.010 & 0.006 \\
\hline January & $-0.130 * * *$ & 0.010 & $-0.153 * * *$ & 0.009 & EHI-A $\geq \gamma_{3}$ & & $-0.109 * *$ & 0.049 & -0.038 & 0.042 \\
\hline February & $-0.137 * * *$ & 0.010 & $-0.158 * * *$ & 0.009 & EHI-A $<\gamma_{1}$ & & -0.015 & 0.023 & 0.005 & 0.006 \\
\hline March & $-0.121 * * *$ & 0.009 & $-0.146^{* * *}$ & 0.008 & EHI-A $\geq \gamma_{1} \&<\gamma_{2}$ & & -0.006 & 0.005 & $-0.021 *$ & 0.012 \\
\hline April & $-0.093^{* * *}$ & 0.009 & $-0.103 * * *$ & 0.008 & EHI-A $\geq \gamma_{2} \&<\gamma_{3}$ & $\checkmark$ & $0.026 * *$ & 0.012 & $0.012 *$ & 0.007 \\
\hline June & $0.105^{* * *}$ & 0.009 & $0.105 * * *$ & 0.008 & EHI-A $\geq \gamma_{3}$ & & $0.241 * * *$ & 0.056 & $0.140 * * *$ & 0.050 \\
\hline $\begin{array}{l}\text { July } \\
\end{array}$ & $0.199 * * *$ & 0.009 & $0.204 * * *$ & 0.008 & EHI-A $<\gamma_{1}$ & & $0.073^{* * * *}$ & 0.026 & $-0.013^{*}$ & 0.007 \\
\hline August & $0.212 * * *$ & 0.010 & $0.205 * * *$ & 0.009 & EHI-A $\geq \gamma_{1} \&<\gamma_{2}$ & 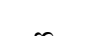 & $-0.013 * *$ & 0.006 & 0.018 & 0.014 \\
\hline September & $0.113 * * *$ & 0.010 & $0.100 * * *$ & 0.009 & EHI-A $\geq \gamma_{2} \&<\gamma_{3}$ & n & -0.013 & 0.015 & $-0.017 * *$ & 0.008 \\
\hline October & 0.011 & 0.010 & -0.013 & 0.009 & EHI-A $\geq \gamma_{3}$ & & 0.010 & 0.070 & -0.045 & 0.062 \\
\hline November & $-0.064 * * *$ & 0.010 & $-0.088 * * *$ & 0.009 & EHI-A $<\gamma_{1}$ & & $-0.091 * * *$ & 0.029 & -0.004 & 0.007 \\
\hline December & $-0.100^{* * *}$ & 0.010 & $-0.119 * * *$ & 0.009 & EHI-A $\geq \gamma_{1} \&<\gamma_{2}$ & + & $0.012 *$ & 0.007 & -0.005 & 0.016 \\
\hline Year 2001 & $0.156^{* * * *}$ & 0.017 & $0.261 * * *$ & 0.010 & EHI-A $\geq \gamma_{2} \&<\gamma_{3}$ & $\vec{\gamma}$ & -0.025 & 0.018 & 0.003 & 0.009 \\
\hline Year 2002 & $0.164 * * *$ & 0.015 & $0.262 * * *$ & 0.010 & EHI-A $\geq \gamma_{3}$ & & $-0.183 * *$ & 0.077 & -0.048 & 0.067 \\
\hline Year 2003 & $0.125 * * *$ & 0.013 & $0.205^{* * * *}$ & 0.009 & EHI-A $<\gamma_{1}$ & & 0.018 & 0.029 & 0.011 & 0.007 \\
\hline Year 2004 & $0.093 * * *$ & 0.011 & $0.163 * * *$ & 0.009 & EHI-A $\geq \gamma_{1} \&<\gamma_{2}$ & 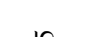 & -0.010 & 0.007 & -0.007 & 0.016 \\
\hline Year 2005 & $0.070 * * *$ & 0.011 & $0.116^{* * * *}$ & 0.009 & EHI-A $\geq \gamma_{2} \&<\gamma_{3}$ & n & $0.035^{*}$ & 0.018 & -0.001 & 0.009 \\
\hline Year 2006 & $0.073 * * *$ & 0.010 & $0.116^{* * * *}$ & 0.009 & EHI-A $\geq \gamma_{3}$ & & 0.007 & 0.085 & 0.055 & 0.068 \\
\hline Year 2007 & $0.099 * * *$ & 0.010 & $0.132 * * *$ & 0.009 & EHI-A $<\gamma_{1}$ & & $0.077 * * *$ & 0.029 & -0.009 & 0.008 \\
\hline Year 2008 & $0.096^{* * * *}$ & 0.011 & $0.130^{* * * *}$ & 0.009 & EHI-A $\geq \gamma_{1} \&<\gamma_{2}$ & 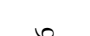 & -0.001 & 0.007 & -0.011 & 0.016 \\
\hline Year 2009 & $0.045 * * *$ & 0.011 & $0.090 * * *$ & 0.009 & EHI-A $\geq \gamma_{2} \&<\gamma_{3}$ & 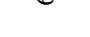 & -0.009 & 0.019 & 0.004 & 0.010 \\
\hline Year 2010 & $0.034 * * *$ & 0.011 & $0.067 * * *$ & 0.009 & EHI-A $\geq \gamma_{3}$ & & $0.164 *$ & 0.089 & -0.024 & 0.072 \\
\hline Year 2011 & $0.038 * * *$ & 0.011 & $0.071 * * *$ & 0.009 & EHI-A $<\gamma_{1}$ & & $-0.084 * * *$ & 0.030 & -0.007 & 0.008 \\
\hline Year 2012 & $0.028 * * *$ & 0.011 & $0.058 * * *$ & 0.009 & EHI-A $\geq \gamma_{1} \&<\gamma_{2}$ & - & 0.010 & 0.007 & $0.031 *$ & 0.017 \\
\hline Year 2013 & -0.003 & 0.011 & $0.020 * *$ & 0.009 & EHI-A $\geq \gamma_{2} \&<\gamma_{3}$ & & -0.027 & 0.019 & -0.005 & 0.010 \\
\hline Year 2014 & $0.020 *$ & 0.010 & $0.039 * * *$ & 0.009 & EHI-A $\geq \gamma_{3}$ & & -0.097 & 0.082 & 0.007 & 0.071 \\
\hline Population >75 & $0.053 *$ & 0.032 & $0.227 * * *$ & 0.009 & EHI-A $<\gamma_{1}$ & & 0.010 & 0.030 & $0.016^{* *}$ & 0.008 \\
\hline Low mortality & $-0.874 * * *$ & 0.037 & $-1.032 * * *$ & 0.010 & EHI-A $\geq \gamma_{1} \&<\gamma_{2}$ & $\infty$ & -0.010 & 0.007 & -0.013 & 0.016 \\
\hline VLow mortality & $-1.379 * * *$ & 0.174 & $-1.680 * * *$ & 0.055 & EHI-A $\geq \gamma_{2} \&<\gamma_{3}$ & & 0.017 & 0.020 & -0.000 & 0.010 \\
\hline & & & & & EHI-A $\geq \gamma_{3}$ & & -0.036 & 0.094 & -0.005 & 0.077 \\
\hline & & & & & EHI-A $<\gamma_{1}$ & & $0.071 * *$ & 0.029 & -0.009 & 0.007 \\
\hline & & & & & EHI-A $\geq \gamma_{1} \&<\gamma_{2}$ & $a$ & -0.004 & 0.007 & -0.012 & 0.016 \\
\hline & & & & & EHI-A $\geq \gamma_{2} \&<\gamma_{3}$ & & 0.013 & 0.019 & -0.005 & 0.010 \\
\hline & & & & & EHI-A $\geq \gamma_{3}$ & & $0.158^{*}$ & 0.092 & 0.076 & 0.077 \\
\hline & & & & & EHI-A $<\gamma_{1}$ & & $-0.075 * * *$ & 0.028 & -0.003 & 0.007 \\
\hline & & & & & EHI-A $\geq \gamma_{1} \&<\gamma_{2}$ & 0 & $0.015^{* * *}$ & 0.007 & 0.006 & 0.016 \\
\hline & & & & & EHI-A $\geq \gamma_{2} \&<\gamma_{3}$ & - & -0.029 & 0.019 & 0.010 & 0.009 \\
\hline & & & & & EHI-A $\geq \gamma_{3}$ & & $-0.147 * *$ & 0.073 & -0.101 & 0.067 \\
\hline & & & & & EHI-A $<\gamma_{1}$ & & 0.010 & 0.028 & 0.008 & 0.007 \\
\hline & & & & & EHI-A $\geq \gamma_{1} \&<\gamma_{2}$ & & -0.011 & 0.007 & 0.021 & 0.016 \\
\hline Temper & ure threshol & $s-$ All & apital Cities & & EHI-A $\geq \gamma_{2} \&<\gamma_{3}$ & - & 0.009 & 0.019 & -0.007 & 0.009 \\
\hline & HI-A $\left(1^{\text {st }}\right.$ Th & esh.) $=$ & 3.51 & & EHI-A $\geq \gamma_{3}$ & & -0.064 & 0.078 & -0.066 & 0.072 \\
\hline & HI-A $\left(2^{\text {nd }} T\right.$ & resh.) $=$ & .74 & & EHI-A $<\gamma_{1}$ & & 0.033 & 0.025 & -0.009 & 0.006 \\
\hline & HI-A $\left(3^{\text {rd }} T\right.$ & resh. $)=$ & .26 & & EHI-A $\geq \gamma_{1} \&<\gamma_{2}$ & $N$ & -0.005 & 0.006 & $-0.023^{*}$ & 0.014 \\
\hline & & & & & EHI-A $\geq \gamma_{2} \&<\gamma_{3}$ & - & 0.020 & 0.016 & -0.004 & 0.008 \\
\hline Temp & ature thresh & $\mid \mathbf{d s}-\mathbf{A l}$ & City Areas & & EHI-A $\geq \gamma_{3}$ & & $0.188^{* * * *}$ & 0.068 & $0.196^{* * * *}$ & 0.061 \\
\hline & HI-A $\left(1^{\text {st }} \mathbf{T l}\right.$ & resh.) $=$ & & & EHI-A $<\gamma_{1}$ & & -0.031 & 0.021 & -0.000 & 0.006 \\
\hline & HI-A $\left(2^{\text {nd }} \mathbf{T}\right.$ & resh.) $=$ & & & EHI-A $\geq \gamma_{1} \&<\gamma_{2}$ & $m$ & $0.011 * *$ & 0.005 & -0.005 & 0.012 \\
\hline & HI-A $\left(3^{\text {rd }} \mathbf{T}\right.$ & resh.) $=$ & & & EHI-A $\geq \gamma_{2} \&<\gamma_{3}$ & - & -0.013 & 0.014 & $0.013^{*}$ & 0.007 \\
\hline & & & & & EHI-A $\geq \gamma_{3}$ & & -0.084 & 0.058 & -0.083 & 0.051 \\
\hline & & & & & EHI-A $<\gamma_{1}$ & & 0.009 & 0.020 & $0.009 *$ & 0.005 \\
\hline & & & & & EHI-A $\geq \gamma_{1} \&<\gamma_{2}$ & $\forall$ & -0.006 & 0.005 & 0.014 & 0.012 \\
\hline & & & & & EHI-A $\geq \gamma_{2} \&<\gamma_{3}$ & - & -0.001 & 0.014 & -0.010 & 0.007 \\
\hline & & & & & EHI-A $\geq \gamma_{3}$ & & -0.072 & 0.061 & -0.073 & 0.053 \\
\hline & & & & & EHI-A $<\gamma_{1}$ & & -0.001 & 0.010 & $-0.008^{* * * *}$ & 0.003 \\
\hline & & & & & EHI-A $\geq \gamma_{1} \&<\gamma_{2}$ & in & -0.001 & 0.003 & -0.010 & 0.007 \\
\hline & & & & & EHI-A $\geq \gamma_{2} \&<\gamma_{3}$ & - & 0.005 & 0.008 & 0.001 & 0.004 \\
\hline & & & & & EHI-A $\geq \gamma_{3}$ & & $0.063^{*}$ & 0.033 & $0.055^{*}$ & 0.030 \\
\hline & & & & & Observations & & 27,0 & & $\overline{81,2}$ & \\
\hline & & & & & R-squared (within) & & 0.19 & & 0.2 & \\
\hline & & & & & R-squared (between) & & 0.92 & & 0.5 & \\
\hline & & & & & F stat & & 66.05 & & 210.2 & \\
\hline & & & & & Number of groups & & 5 & & 15 & \\
\hline
\end{tabular}

Note: Variables for Wednesday, May and the Year 2015 are not included and absorbed into the constant. Statistical Significance is indicated as: $* * *$ for $\mathrm{p}<0.01, * *$ for $\mathrm{p}<0.05, *$ for $\mathrm{p}<0.1$. 
Table 6A - Threshold regression model results - Number of deaths per region Reduced model

\begin{tabular}{|c|c|c|c|c|c|c|c|c|c|c|}
\hline \multirow[b]{2}{*}{ Variables } & \multicolumn{2}{|c|}{ All Capital Cities } & \multicolumn{2}{|c|}{ All City Areas } & \multirow[b]{2}{*}{ Variables } & \multirow{2}{*}{$\begin{array}{l}\text { No. } \\
\text { of } \\
\text { lags }\end{array}$} & \multicolumn{2}{|c|}{ All Capital Cities } & \multicolumn{2}{|c|}{ All City Areas } \\
\hline & Coef. & SE & Coef. & SE & & & Coef. & SE & Coef. & SE \\
\hline Constant & $31.501 * * *$ & 4.774 & $3.668 * * *$ & 0.451 & EHI-A $<\gamma_{1}$ & \multirow{4}{*}{0} & 0.139 & 0.310 & $0.042 *$ & 0.023 \\
\hline Monday & $-0.652 * * *$ & 0.167 & $-0.198^{* * *}$ & 0.049 & EHI-A $\geq \gamma_{1} \&<\gamma_{2}$ & & $0.136^{*}$ & 0.077 & 0.042 & 0.030 \\
\hline Tuesday & $-0.295^{*}$ & 0.167 & -0.064 & 0.049 & EHI-A $\geq \gamma_{2} \&<\gamma_{3}$ & & 0.037 & 0.117 & -0.230 ** & 0.100 \\
\hline Thursday & 0.232 & 0.167 & 0.059 & 0.049 & EHI-A $\geq \gamma_{3}$ & & -0.853 & 0.558 & $-0.530 * *$ & 0.262 \\
\hline Friday & $0.855^{* * * *}$ & 0.167 & $0.246 * * *$ & 0.049 & EHI-A $<\gamma_{1}$ & & 0.077 & 0.542 & $0.080^{\text {** }}$ & 0.037 \\
\hline Saturday & $0.515 * * *$ & 0.167 & $0.172 * * *$ & 0.050 & EHI-A $\geq \gamma_{1} \&<\gamma_{2}$ & - & $0.254 * *$ & 0.123 & 0.058 & 0.051 \\
\hline Sunday & $-0.616^{* * * *}$ & 0.167 & $-0.195 * * *$ & 0.050 & EHI-A $\geq \gamma_{2} \&<\gamma_{3}$ & - & $0.374 *$ & 0.211 & 0.196 & 0.190 \\
\hline January & $-4.027 * * *$ & 0.234 & $-1.325 * * *$ & 0.070 & EHI-A $\geq \gamma_{3}$ & & -1.822 & 1.109 & -0.731 & 0.518 \\
\hline February & $-4.178 * * *$ & 0.228 & $-1.374 * * *$ & 0.067 & EHI-A $<\gamma_{1}$ & & -0.607 & 0.540 & -0.030 & 0.037 \\
\hline March & $-3.807 * * *$ & 0.218 & $-1.239 * * *$ & 0.064 & EHI-A $\geq \gamma_{1} \&<\gamma_{2}$ & $\alpha$ & 0.015 & 0.124 & $0.117^{* * *}$ & 0.053 \\
\hline April & $-2.610 * * *$ & 0.218 & $-0.861 * * *$ & 0.064 & EHI-A $\geq \gamma_{2} \&<\gamma_{3}$ & त & 0.350 & 0.221 & 0.347 & 0.213 \\
\hline June & $2.707 * * *$ & 0.219 & $0.862 * * *$ & 0.065 & EHI-A $\geq \gamma_{3}$ & & $6.330 * * *$ & 1.230 & $2.569 * * *$ & 0.563 \\
\hline July & $5.110 * * *$ & 0.221 & $1.617 * * *$ & 0.066 & EHI-A $<\gamma_{1}$ & & 0.629 & 0.518 & -0.058 & 0.036 \\
\hline August & $5.099 * * *$ & 0.228 & $1.607 * * *$ & 0.068 & EHI-A $\geq \gamma_{1} \&<\gamma_{2}$ & $m$ & $-0.355^{* * * *}$ & 0.124 & $-0.134 * *$ & 0.056 \\
\hline September & $2.310^{* * *}$ & 0.236 & $0.738 * * *$ & 0.071 & EHI-A $\geq \gamma_{2} \&<\gamma_{3}$ & 1. & $-0.390^{*}$ & 0.233 & -0.343 & 0.228 \\
\hline October & $-0.540 * *$ & 0.232 & $-0.209 * * *$ & 0.069 & EHI-A $\geq \gamma_{3}$ & & $-2.732 *$ & 1.411 & -0.309 & 0.579 \\
\hline November & $-2.511 * * *$ & 0.236 & $-0.835^{* * * *}$ & 0.070 & EHI-A $<\gamma_{1}$ & & -0.579 & 0.492 & -0.008 & 0.036 \\
\hline December & $-3.408 * * *$ & 0.232 & $-1.129 * * *$ & 0.069 & EHI-A $\geq \gamma_{1} \&<\gamma_{2}$ & + & 0.047 & 0.122 & 0.015 & 0.055 \\
\hline Year 2001 & $-5.440 * * *$ & 0.417 & $-1.067 * * *$ & 0.082 & EHI-A $\geq \gamma_{2} \&<\gamma_{3}$ & 政 & -0.099 & 0.236 & 0.181 & 0.218 \\
\hline Year 2002 & $-4.588 * * *$ & 0.356 & $-0.928 * * *$ & 0.078 & EHI-A $\geq \gamma_{3}$ & & -2.039 & 1.262 & $-2.145^{* * *}$ & 0.536 \\
\hline Year 2003 & $-5.347 * * *$ & 0.312 & $-1.266^{* * * *}$ & 0.076 & EHI-A $<\gamma_{1}$ & & 0.188 & 0.494 & 0.020 & 0.035 \\
\hline Year 2004 & $-5.582 * * *$ & 0.278 & $-1.417 * * *$ & 0.074 & EHI-A $\geq \gamma_{1} \&<\gamma_{2}$ & 10 & 0.115 & 0.121 & 0.007 & 0.054 \\
\hline Year 2005 & $-6.011 * * *$ & 0.257 & $-1.673 * * *$ & 0.074 & EHI-A $\geq \gamma_{2} \&<\gamma_{3}$ & 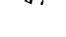 & 0.334 & 0.230 & 0.053 & 0.216 \\
\hline Year 2006 & $-5.215 * * *$ & 0.251 & $-1.448 * * *$ & 0.073 & EHI-A $\geq \gamma_{3}$ & & 1.752 & 1.144 & $1.424 * * *$ & 0.552 \\
\hline Year 2007 & $-3.755 * * *$ & 0.252 & $-0.989 * * *$ & 0.073 & EHI-A $<\gamma_{1}$ & & 0.122 & 0.272 & -0.028 & 0.021 \\
\hline Year 2008 & $-2.815 * * *$ & 0.258 & $-0.720^{* * *}$ & 0.073 & EHI-A $\geq \gamma_{1} \&<\gamma_{2}$ & 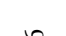 & -0.115 & 0.070 & -0.027 & 0.033 \\
\hline Year 2009 & $-3.216^{* * *}$ & 0.270 & $-0.774 * * *$ & 0.074 & EHI-A $\geq \gamma_{2} \&<\gamma_{3}$ & 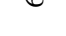 & $-0.275 * *$ & 0.134 & -0.048 & 0.131 \\
\hline Year 2010 & $-2.764 * * *$ & 0.268 & $-0.677 * * *$ & 0.074 & EHI-A $\geq \gamma_{3}$ & & 0.052 & 0.645 & 0.125 & 0.315 \\
\hline Year 2011 & $-1.741 * * *$ & 0.261 & $-0.397 * * *$ & 0.073 & EHI-A $<\gamma_{1}$ & & & & & \\
\hline Year 2012 & $-1.232 * * *$ & 0.262 & $-0.285 * * *$ & 0.073 & EHI-A $\geq \gamma_{1} \&<\gamma_{2}$ & - & & & & \\
\hline Year 2013 & $-1.230 * * *$ & 0.259 & $-0.309 * * *$ & 0.073 & EHI-A $\geq \gamma_{2} \&<\gamma_{3}$ & & & & & \\
\hline Year 2014 & 0.236 & 0.250 & 0.101 & 0.073 & EHI-A $\geq \gamma_{3}$ & & & & & \\
\hline Population >75 & $2.676 * * *$ & 0.776 & $1.946 * * *$ & 0.069 & EHI-A $<\gamma_{1}$ & & & & & \\
\hline Low mortality & $-16.925 * * *$ & 0.905 & $-7.288 * * *$ & 0.081 & EHI-A $\geq \gamma_{1} \&<\gamma_{2}$ & $\infty$ & & & & \\
\hline VLow mortality & $-37.408 * * *$ & 4.260 & $-10.354 * * *$ & 0.446 & EHI-A $\geq \gamma_{2} \&<\gamma_{3}$ & & & & & \\
\hline & & & & & EHI-A $\geq \gamma_{3}$ & & & & & \\
\hline & & & & & EHI-A $<\gamma_{1}$ & & & & & \\
\hline & & & & & EHI-A $\geq \gamma_{1} \&<\gamma_{2}$ & 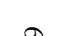 & & & & \\
\hline & & & & & EHI-A $\geq \gamma_{2} \&<\gamma_{3}$ & Tr & & & & \\
\hline & & & & & EHI-A $\geq \gamma_{3}$ & & & & & \\
\hline & & & & & EHI-A $<\gamma_{1}$ & & & & & \\
\hline & & & & & EHI-A $\geq \gamma_{1} \&<\gamma_{2}$ & 0 & & & & \\
\hline & & & & & EHI-A $\geq \gamma_{2} \&<\gamma_{3}$ & & & & & \\
\hline & & & & & EHI-A $\geq \gamma_{3}$ & & & & & \\
\hline & & & & & EHI-A $<\gamma_{1}$ & & & & & \\
\hline & & & & & EHI-A $\geq \gamma_{1} \&<\gamma_{2}$ & $=$ & & anly s & $x$ laos annlied & \\
\hline Temp & ature thresho & - All & pital Cities & & EHI-A $\geq \gamma_{2} \&<\gamma_{3}$ & - & & Oiny s & A lags appines & \\
\hline & EHI-A $\left(1^{\text {st }}\right.$ T & sh.) $=$ & & & EHI-A $\geq \gamma_{3}$ & & & & & \\
\hline & EHI-A $\left(2^{\text {nd }} 7\right.$ & esh.) $=$ & & & EHI-A $<\gamma_{1}$ & & & & & \\
\hline & EHI-A $\left(3^{\text {rd }} 7\right.$ & esh.) $=$ & & & EHI-A $\geq \gamma_{1} \&<\gamma_{2}$ & $\mathrm{a}$ & & & & \\
\hline & & & & & EHI-A $\geq \gamma_{2} \&<\gamma_{3}$ & & & & & \\
\hline Ten & erature thresl & Is-All & ity Areas & & EHI-A $\geq \gamma_{3}$ & & & & & \\
\hline & EHI-A $\left(1^{\text {st }} \mathbf{T}\right.$ & esh.) $=$ & & & EHI-A $<\gamma_{1}$ & & & & & \\
\hline & EHI-A $\left(2^{\text {nd }} 7\right.$ & esh.) $=$ & & & EHI-A $\geq \gamma_{1} \&<\gamma_{2}$ & $m$ & & & & \\
\hline & EHI-A $\left(3^{\text {rd }} 7\right.$ & esh.) $=$ & & & EHI-A $\geq \gamma_{2} \&<\gamma_{3}$ & & & & & \\
\hline & & & & & EHI-A $\geq \gamma_{3}$ & & & & & \\
\hline & & & & & EHI-A $<\gamma_{1}$ & & & & & \\
\hline & & & & & EHI-A $\geq \gamma_{1} \&<\gamma_{2}$ & 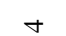 & & & & \\
\hline & & & & & EHI-A $\geq \gamma_{2} \&<\gamma_{3}$ & & & & & \\
\hline & & & & & EHI-A $\geq \gamma_{3}$ & & & & & \\
\hline & & & & & EHI-A $<\gamma_{1}$ & & & & & \\
\hline & & & & & EHI-A $\geq \gamma_{1} \&<\gamma_{2}$ & $n$ & & & & \\
\hline & & & & & EHI-A $\geq \gamma_{2} \&<\gamma_{3}$ & - & & & & \\
\hline & & & & & EHI-A $\geq \gamma_{3}$ & & & & & \\
\hline & & & & & Observations & & 27, & & 81,39 & \\
\hline & & & & & R-squared (within) & & 0.2 & & 0.20 & \\
\hline & & & & & R-squared (between) & & 0.0 & & 0.019 & \\
\hline & & & & & F stat & & 144.3 & & 327.90 & \\
\hline & & & & & Number of groups & & 5 & & 15 & \\
\hline
\end{tabular}

Note: Variables for Wednesday, May and the Year 2015 are not included and absorbed into the constant. Statistical Significance is indicated as: $* * *$ for $\mathrm{p}<0.01, * *$ for $\mathrm{p}<0.05, *$ for $\mathrm{p}<0.1$. 
Table 7A - Threshold regression model results - Number of deaths per 100,000 Reduced model

\begin{tabular}{|c|c|c|c|c|c|c|c|c|c|c|}
\hline \multirow{2}{*}{ Variables } & \multicolumn{2}{|c|}{ All Capital Cities } & \multicolumn{2}{|c|}{ All City Areas } & \multirow{2}{*}{ Variables } & \multirow{2}{*}{$\begin{array}{c}\text { No. } \\
\text { of } \\
\text { lags }\end{array}$} & \multicolumn{2}{|c|}{ All Capital Cities } & \multicolumn{2}{|c|}{ All City Areas } \\
\hline & Coef. & SE & Coef. & SE & & & Coef. & SE & Coef. & SE \\
\hline Constant & $1.347 * * *$ & 0.195 & $0.231^{* * * *}$ & 0.056 & EHI-A $<\gamma_{1}$ & \multirow{4}{*}{0} & 0.002 & 0.003 & $0.006^{* *}$ & 0.003 \\
\hline Monday & $-0.026 * * *$ & 0.007 & $-0.022 * * *$ & 0.006 & EHI-A $\geq \gamma_{1} \&<\gamma_{2}$ & & 0.013 & 0.008 & 0.001 & 0.004 \\
\hline Tuesday & -0.009 & 0.007 & -0.009 & 0.006 & EHI-A $\geq \gamma_{2} \&<\gamma_{3}$ & & -0.001 & 0.006 & -0.007 & 0.024 \\
\hline Thursday & $0.012 *$ & 0.007 & 0.008 & 0.006 & EHI-A $\geq \gamma_{3}$ & & $-0.042 *$ & 0.023 & $-0.062 *$ & 0.032 \\
\hline Friday & $0.031 * * *$ & 0.007 & $0.030^{* * * *}$ & 0.006 & EHI-A $<\gamma_{1}$ & & $0.014 * * *$ & 0.005 & 0.006 & 0.004 \\
\hline Saturday & $0.024 * * *$ & 0.007 & $0.020^{* * * *}$ & 0.006 & EHI-A $\geq \gamma_{1} \&<\gamma_{2}$ & $\theta_{3}$ & 0.014 & 0.015 & 0.010 & 0.006 \\
\hline Sunday & $-0.016^{* *}$ & 0.007 & $-0.021 * * *$ & 0.006 & EHI-A $\geq \gamma_{2} \&<\gamma_{3}$ & 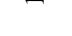 & 0.008 & 0.011 & -0.037 & 0.047 \\
\hline January & $-0.137 * * *$ & 0.010 & $-0.163^{* * *}$ & 0.009 & EHI-A $\geq \gamma_{3}$ & & $-0.076^{*}$ & 0.045 & -0.060 & 0.064 \\
\hline February & $-0.142 * * *$ & 0.009 & $-0.164 * * *$ & 0.008 & EHI-A $<\gamma_{1}$ & & -0.003 & 0.005 & -0.002 & 0.004 \\
\hline March & $-0.124 * * *$ & 0.009 & $-0.151 * * *$ & 0.008 & EHI-A $\geq \gamma_{1} \&<\gamma_{2}$ & $\theta$ & 0.004 & 0.015 & $0.013^{* *}$ & 0.007 \\
\hline April & $-0.093 * * *$ & 0.009 & $-0.104 * * *$ & 0.008 & EHI-A $\geq \gamma_{2} \&<\gamma_{3}$ & $N$ & $0.021^{*}$ & 0.012 & $0.094 *$ & 0.054 \\
\hline June & $0.105^{* * *}$ & 0.009 & $0.103^{* * * *}$ & 0.008 & EHI-A $\geq \gamma_{3}$ & & $0.247 * * *$ & 0.050 & $0.273^{* * *} *$ & 0.070 \\
\hline July & $0.197 * * *$ & 0.009 & $0.199 * * *$ & 0.008 & EHI-A $<\gamma_{1}$ & & $-0.010 * *$ & 0.005 & -0.005 & 0.004 \\
\hline August & $0.206 * * *$ & 0.009 & $0.196^{* * * *}$ & 0.008 & EHI-A $\geq \gamma_{1} \&<\gamma_{2}$ & $m$ & $-0.034 * *$ & 0.016 & $-0.019 * * *$ & 0.007 \\
\hline September & $0.105 * * *$ & 0.010 & $0.090 * * *$ & 0.009 & EHI-A $\geq \gamma_{2} \&<\gamma_{3}$ & $m$ & -0.016 & 0.012 & -0.048 & 0.062 \\
\hline October & 0.002 & 0.009 & $-0.024 * * *$ & 0.009 & EHI-A $\geq \gamma_{3}$ & & -0.068 & 0.058 & -0.061 & 0.072 \\
\hline November & $-0.074 * * *$ & 0.010 & $-0.099 * * *$ & 0.009 & EHI-A $<\gamma_{1}$ & & 0.000 & 0.005 & -0.002 & 0.004 \\
\hline December & $-0.108 * * *$ & 0.009 & $-0.129 * * *$ & 0.009 & EHI-A $\geq \gamma_{1} \&<\gamma_{2}$ & +1 & $0.037 * *$ & 0.016 & 0.005 & 0.007 \\
\hline Year 2001 & $0.154 * * *$ & 0.017 & $0.264 * * *$ & 0.010 & EHI-A $\geq \gamma_{2} \&<\gamma_{3}$ & 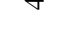 & -0.013 & 0.013 & 0.027 & 0.055 \\
\hline Year 2002 & $0.162 * * *$ & 0.015 & $0.262 * * *$ & 0.010 & EHI-A $\geq \gamma_{3}$ & & $-0.121 * *$ & 0.052 & $-0.217 * * *$ & 0.066 \\
\hline Year 2003 & $0.124 * * *$ & 0.013 & $0.205 * * *$ & 0.009 & EHI-A $<\gamma_{1}$ & & 0.002 & 0.005 & 0.002 & 0.004 \\
\hline Year 2004 & $0.093 * * *$ & 0.011 & 0.163 *** & 0.009 & EHI-A $\geq \gamma_{1} \&<\gamma_{2}$ & 10 & -0.018 & 0.015 & -0.001 & 0.007 \\
\hline Year 2005 & $0.069 * * *$ & 0.011 & $0.117 * * *$ & 0.009 & EHI-A $\geq \gamma_{2} \&<\gamma_{3}$ & $n$ & $0.024 * *$ & 0.012 & 0.016 & 0.051 \\
\hline Year 2006 & $0.073 * * *$ & 0.010 & $0.116^{* * * *}$ & 0.009 & EHI-A $\geq \gamma_{3}$ & & 0.072 & 0.047 & 0.169 ** & 0.068 \\
\hline Year 2007 & $0.099 * * *$ & 0.010 & $0.133^{* * * *}$ & 0.009 & EHI-A $<\gamma_{1}$ & & -0.002 & 0.003 & $\begin{array}{l}-0.002 \\
\end{array}$ & 0.003 \\
\hline Year 2008 & $0.096 * * *$ & 0.011 & $0.130 * * *$ & 0.009 & EHI-A $\geq \gamma_{1} \&<\gamma_{2}$ & 0 & -0.005 & 0.009 & -0.002 & 0.004 \\
\hline Year 2009 & $0.044 * * *$ & 0.011 & $0.089 * * *$ & 0.009 & EHI-A $\geq \gamma_{2} \&<\gamma_{3}$ & 6 & $-0.018 * *$ & 0.007 & -0.016 & 0.033 \\
\hline Year 2010 & $0.034 * * *$ & 0.011 & $0.067 * * *$ & 0.009 & EHI-A $\geq \gamma_{3}$ & & 0.014 & 0.026 & -0.017 & 0.039 \\
\hline Year 2011 & $0.037 * * *$ & 0.011 & $0.072 * * *$ & 0.009 & EHI-A $<\gamma_{1}$ & & & & & \\
\hline Year 2012 & $0.027 * *$ & 0.011 & 0.058 *** & 0.009 & EHI-A $\geq \gamma_{1} \&<\gamma_{2}$ & 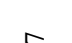 & & & & \\
\hline Year 2013 & -0.003 & 0.011 & $0.020 * *$ & 0.009 & EHI-A $\geq \gamma_{2} \&<\gamma_{3}$ & $\pi$ & & & & \\
\hline Year 2014 & $0.019^{*}$ & 0.010 & $0.039 * * *$ & 0.009 & EHI-A $\geq \gamma_{3}$ & & & & & \\
\hline Population >75 & 0.046 & 0.032 & $0.227 * * *$ & 0.009 & EHI-A $<\gamma_{1}$ & & & & & \\
\hline Low mortality & $-0.878 * * *$ & 0.037 & $-1.032 * * *$ & 0.010 & EHI-A $\geq \gamma_{1} \&<\gamma_{2}$ & $\infty$ & & & & \\
\hline VLow mortality & $-1.364 * * *$ & 0.174 & $-1.685^{* * *}$ & 0.055 & EHI-A $\geq \gamma_{2} \&<\gamma_{3}$ & $\infty$ & & & & \\
\hline & & & & & EHI-A $\geq \gamma_{3}$ & & & & & \\
\hline & & & & & EHI-A $<\gamma_{1}$ & & & & & \\
\hline & & & & & EHI-A $\geq \gamma_{1} \&<\gamma_{2}$ & 7 & & & & \\
\hline & & & & & EHI-A $\geq \gamma_{2} \&<\gamma_{3}$ & $a$ & & & & \\
\hline & & & & & EHI-A $\geq \gamma_{3}$ & & & & & \\
\hline & & & & & EHI-A $<\gamma_{1}$ & & & & & \\
\hline & & & & & EHI-A $\geq \gamma_{1} \&<\gamma_{2}$ & 0 & & & & \\
\hline & & & & & EHI-A $\geq \gamma_{2} \&<\gamma_{3}$ & $=$ & & & & \\
\hline & & & & & EHI-A $\geq \gamma_{3}$ & & & & & \\
\hline & & & & & EHI-A $<\gamma_{1}$ & & & & & \\
\hline & & & & & EHI-A $\geq \gamma_{1} \&<\gamma_{2}$ & - & & nly si & nnlied & \\
\hline Tempc & ature thresh & s-All & Ipital Cities & & EHI-A $\geq \gamma_{2} \&<\gamma_{3}$ & - & & - oniy si & Tags appired & \\
\hline & EHI-A $\left(1^{\text {st }}\right)$ & esh.) $=$ & & & EHI-A $\geq \gamma_{3}$ & & & & & \\
\hline & EHI-A $\left(2^{\text {nd }} 7\right.$ & resh.) $=$ & & & EHI-A $<\gamma_{1}$ & & & & & \\
\hline & EHI-A $\left(3^{\text {rd }} 7\right.$ & resh.) $=$ & & & EHI-A $\geq \gamma_{1} \&<\gamma_{2}$ & $N$ & & & & \\
\hline & & & & & EHI-A $\geq \gamma_{2} \&<\gamma_{3}$ & - & & & & \\
\hline Tem & rature thres & $\mid \mathbf{d s - A |}$ & ity Areas & & EHI-A $\geq \gamma_{3}$ & & & & & \\
\hline & EHI-A (1 $\left.{ }^{\text {st }}\right]$ & resh.) $=$ & & & EHI-A $<\gamma_{1}$ & & & & & \\
\hline & EHI-A $\left(2^{\text {nd }}\right)$ & resh.) $=$ & & & EHI-A $\geq \gamma_{1} \&<\gamma_{2}$ & $m$ & & & & \\
\hline & EHI-A $\left(3^{\text {rd }}\right)$ & resh.) $=$ & & & EHI-A $\geq \gamma_{2} \&<\gamma_{3}$ & & & & & \\
\hline & & & & & EHI-A $\geq \gamma_{3}$ & & & & & \\
\hline & & & & & EHI-A $<\gamma_{1}$ & & & & & \\
\hline & & & & & EHI-A $\geq \gamma_{1} \&<\gamma_{2}$ & $\nabla$ & & & & \\
\hline & & & & & EHI-A $\geq \gamma_{2} \&<\gamma_{3}$ & & & & & \\
\hline & & & & & EHI-A $\geq \gamma_{3}$ & & & & & \\
\hline & & & & & EHI-A $<\gamma_{1}$ & & & & & \\
\hline & & & & & EHI-A $\geq \gamma_{1} \&<\gamma_{2}$ & $n$ & & & & \\
\hline & & & & & EHI-A $\geq \gamma_{2} \&<\gamma_{3}$ & - & & & & \\
\hline & & & & & EHI-A $\geq \gamma_{3}$ & & & & & \\
\hline & & & & & \begin{tabular}{|l} 
Observations \\
\end{tabular} & & 27,1 & & 81,39 & \\
\hline & & & & & \begin{tabular}{|l|} 
R-squared (within) \\
\end{tabular} & & 0.19 & & 0.202 & \\
\hline & & & & & R-squared (between) & & 0.92 & & 0.550 & \\
\hline & & & & & F stat & & 103.6 & & $331.85^{\prime}$ & \\
\hline & & & & & Number of groups & & 5 & & 15 & \\
\hline
\end{tabular}

Note: Variables for Wednesday, May and the Year 2015 are not included and absorbed into the constant. Statistical Significance is indicated as: $* * *$ for $\mathrm{p}<0.01, * *$ for $\mathrm{p}<0.05, *$ for $\mathrm{p}<0.1$. 


\section{Box 1A - Background on short-term mortality displacement}

The debate surrounding the magnitude of temperature-related mortality that coincided with certain extreme heat events has led to a range of studies that measure short-term mortality displacement (Benmarhnia et al. 2016; Braga et al. 2001; Hajat et al. 2005; Kaiser et al. 2007; Le Tertre et al. 2006; Toulemon and Barbieri 2008). The key issue being the extent to which temperature-related deaths coincided with people who were likely to die from another cause within a short amount of time. Previous studies have found differing results on the extent to which mortality displacement occurs. A study that utilised data from Brisbane found that heat tended to be related to a short displacement period of between two days and one week (Yu et al. 2011). Saha et al. (2013) utilised a short-term mortality displacement period that was limited to a maximum of 15 days after the extreme heat event and found that mortality displacement varied with the severity of heat events and the city focused upon. A similar time-frame for short-term displacement is used in this paper as it is consistent with the findings of Guo et al. (2014). Guo et al. (2014) found that the duration of cold-related mortality lasted for 10 days after the event and for heat-related mortality it lasted 3 days. Note that distinguishing between shortterm and long-term mortality displacement is important as a previous study associated high respiratory, cardiovascular and influenza mortality in winter with lower temperature effects in the following summer (Rocklöv et al. 2009). 